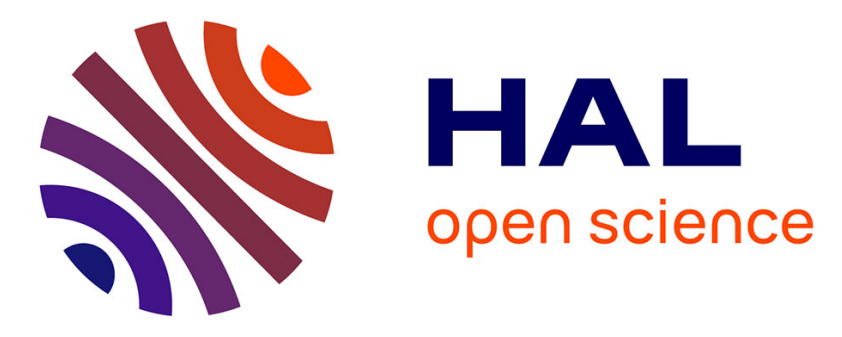

\title{
Upgrading of pine tannin biochars as electrochemical capacitor electrodes
}

Sara Pérez-Rodríguez, Oscar Pinto, Maria T Izquierdo, Cristina Segura, Po S Poon, Alain Celzard, Juan Matos, Vanessa Fierro

\section{- To cite this version:}

Sara Pérez-Rodríguez, Oscar Pinto, Maria T Izquierdo, Cristina Segura, Po S Poon, et al.. Upgrading of pine tannin biochars as electrochemical capacitor electrodes. Journal of Colloid and Interface Science, 2021, 601, pp.863-876. 10.1016/j.jcis.2021.05.162 . hal-03387807

\section{HAL Id: hal-03387807 \\ https://hal.univ-lorraine.fr/hal-03387807}

Submitted on 20 Oct 2021

HAL is a multi-disciplinary open access archive for the deposit and dissemination of scientific research documents, whether they are published or not. The documents may come from teaching and research institutions in France or abroad, or from public or private research centers.
L'archive ouverte pluridisciplinaire HAL, est destinée au dépôt et à la diffusion de documents scientifiques de niveau recherche, publiés ou non, émanant des établissements d'enseignement et de recherche français ou étrangers, des laboratoires publics ou privés. 


\section{Upgrading of pine tannin biochars as electrochemical capacitor}

\section{electrodes}

Sara Pérez-Rodríguez ${ }^{\mathrm{a}, *}$, Oscar Pinto $^{\mathrm{b}, \mathrm{c}}$, Maria T. Izquierdo ${ }^{\mathrm{d}}$, Cristina Segura $^{\mathrm{e}}$, Po S. Poon $^{\mathrm{e}}$, Alain Celzard $^{\mathrm{a}}$, Juan Matos $^{\mathrm{f}}, *$, Vanessa Fierro ${ }^{\mathrm{a}, *}$

${ }^{a}$ Université de Lorraine, CNRS, IJL, F-88000, Epinal, France

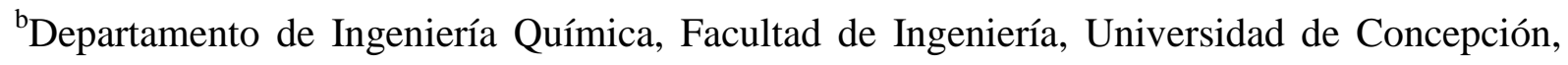
Barrio Universitario s/n, Chile.

${ }^{c}$ ANID-Millennium Science Initiative Program, Millennium Nuclei on Catalytic Process towards Sustainable Chemistry (CSC), Chile.

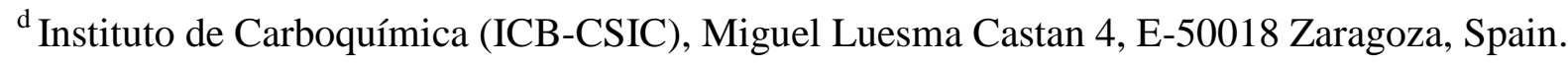
${ }^{\mathrm{e}}$ Unidad de Desarrollo Tecnológico (UDT), Universidad de Concepción, Barrio Universitario s/n, Concepción, Chile.

${ }^{\mathrm{f}}$ Instituto de Ciencias Químicas Aplicadas, Facultad de Ingeniería, Universidad Autónoma de Chile, 8900000 Santiago, Chile.

*Corresponding Authors:

S. Pérez-Rodríguez. Email: sara.perez-rodriguez@univ-lorraine.fr. Phone: +33 (0)372 749 677

J. Matos. Email: juan.matos@uautonoma.cl.Phone: +56993798340

V. Fierro. Email: Vanessa.Fierro@univ-lorraine.fr. Phone: +33 (0)372 749677 


\begin{abstract}
Biochar derived from the pyrolysis of pine tannin is a green and available by-product of oil manufacturing that presents interesting features after having been activated by $\mathrm{KOH}$ at 650 ${ }^{\circ} \mathrm{C}$. Different weight ratios of $\mathrm{KOH}$ to biochar were used and the resulting activated carbons (ACs) presented highly developed specific surface areas of up to $2190 \mathrm{~m}^{2} \mathrm{~g}^{-1}$, well-connected porosity and high oxygen content, leading to enhanced electrochemical performance when used as electrochemical capacitor electrodes in a $1 \mathrm{M} \mathrm{H}_{2} \mathrm{SO}_{4}$ aqueous electrolyte. Galvanostatic charge/discharge experiments evidenced that the best material achieved a maximum electrode capacitance of up to $232 \mathrm{~F} \mathrm{~g}^{-1}$ (at $0.5 \mathrm{~A} \mathrm{~g}^{-1}$ ) with a capacitance retention of $70 \%$ at $10 \mathrm{~A} \mathrm{~g}^{-1}$ using commercial mass loadings (i.e., approx. $10 \mathrm{mg} \mathrm{cm}^{-2}$ ). In addition, long cycling stability with a residual capacitance of 92 to $94 \%$ after 10,000 cycles at $5 \mathrm{~A} \mathrm{~g}^{-1}$ was achieved. These results prove that ACs derived from pine tannin biochars have great potential for their commercial use as electrochemical energy storage devices.
\end{abstract}

Keywords. Tannin; biochars; pyrolysis; $\mathrm{KOH}$ activation; electrochemical capacitors. 
Abbreviations:

Activated carbons (ACs)

Activating ratio (AR)

Brunauer-Emmet-Teller (BET)

Cyclic voltammetry (CV)

Dubinin-Radushkevich (DR)

Electrochemical impedance spectroscopy (EIS)

Galvanostatic charge/discharge (GCD)

Non-local density functional theory model for heterogeneous surface (NLDFT-HS)

Open circuit potential (OCP)

Pore size distribution (PSD)

Electrochemical capacitors (ECs)

TBC (tannin biochar).

Transmission electron microscopy (TEM)

X-ray photoelectron spectroscopy (XPS) 


\section{Introduction}

The world market of electrochemical capacitors (ECs) is growing rapidly to cope with intermittent renewable sources, short-term applications or quick regeneration in hybrid and electric vehicles [1,2]. Charge storage in ECs occurs through the generation of an electrostatic double layer (EDL) by the interaction of ions from an electrolyte and a conductive porous electrode surface (conventionally activated carbons, ACs). Due to the high surface area of ACs and the short ion-to-electrode distance, ECs provide greater capacitance than conventional capacitors, while delivering charge faster than batteries [1,3]. However, the main disadvantage of ECs is their relative low specific energy compared to batteries $[1,3]$.

In recent years, many efforts have been made to develop highly efficient ECs. Several approaches have been proposed, such as the development of nanostructured carbon materials with a high surface area and hierarchical porosity to increase the capacitance and reduce the diffusion resistance thanks to non-tortuous channels, and thus obtain high-rate capabilities [46]. Modification of the surface chemistry by introducing heteroatoms (such as $\mathrm{O}, \mathrm{N}$ or $\mathrm{S}$ ) has also been explored as a strategy to improve performance by surface redox reactions (pseudocapacitance charge) $[1,5]$. However, the synthesis of these advanced carbon materials often requires complex, long and expensive methodologies, involving high carbonization temperatures and petrochemical precursors such as coal, hydrocarbons, phenol, etc., which limit their widespread commercialization.

A further attempt to develop "greener" and more competitive ECs has been made by using ACs derived from highly available agricultural/wood waste as the active material [6-9]. For instance, coffee grounds [10,11], sugar cane [12], human hair [13] or cotton [14], among others, have been successfully used as precursors to develop EDL capacitors. Different methods of chemical $\left(\mathrm{KOH}, \mathrm{H}_{3} \mathrm{PO}_{4}\right.$ or $\left.\mathrm{ZnCl}_{2}\right)$, physical $\left(\mathrm{CO}_{2}\right.$, air or steam) and microwaveassisted activation have been studied for the synthesis of ACs [7,15]. As a general trend, a 
more developed porosity has been reported by chemical activation, especially with $\mathrm{KOH}$ $[15,16]$. Beside the oxidation of carbon by intercalation of metallic potassium in the porous matrix, such outstanding pore texture development may result from further carbon gasification by $\mathrm{CO}_{2}$ and $\mathrm{H}_{2} \mathrm{O}$ obtained as by-products during $\mathrm{KOH}$ activation. In addition, good control of pore size and narrow pore distributions can be achieved by adjusting the $\mathrm{KOH}$ amount and the activation temperature [15]. Consequently, porous materials with high electrochemical capacitance have been successfully obtained by pyrolysis/KOH activation of biomass resources [10,11,13,17-23]. For instance, Yun et al. [24] designed high-performance EDL capacitor electrodes based on microporous carbon nanoplates prepared by $\mathrm{KOH}$ activation of regenerated silk proteins. The materials exhibited a specific capacitance of ca. $230 \mathrm{~F} \mathrm{~g}^{-1}$ in $1 \mathrm{M} \mathrm{H}_{2} \mathrm{SO}_{4}\left(\right.$ at $\left.0.5 \mathrm{~A} \mathrm{~g}^{-1}\right)$.

Similarly, condensed tannins have also been proposed as cost-effective, non-toxic and renewable precursors for the synthesis of carbon materials. These polyphenolic compounds can be extracted from a wide variety of plants, trees and fruit residues. In addition to their high natural availability, tannins present the advantage of a high reactivity and autocondensation ability, which leads to the formation of polymeric units (even in the absence of crosslinkers) with a high carbon yield after pyrolysis [25,26]. A wide family of carbonaceous materials, including ordered mesoporous carbons [27,28], gels [26,29,30], foams [31] or microspheres [32], have been obtained by carbonization of a phenolic resin derived from tannin, previously obtained by hydrothermal, sol-gel, or hard/soft templating routes. However, the application of tannin-derived porous carbon materials as electrodes of ECs has been less explored [2,33-37].

In this study, we used biochars produced from the bark of Pinus radiata. The consumption of Pinus radiata in Chile reached around 35 million $\mathrm{m}^{3}$ of debarked wood in 2015 [38], leading to a production of around 3.5 million $\mathrm{m}^{3}$ of bark per year [39], which is mainly used for 
energy generation and, to a lesser extent, as a soil amendment and for oil production. Herein, we have used a biochar that is a by-product of the pyrolysis of pine tannins for oil production to make ECs electrodes after $\mathrm{KOH}$ activation at mild temperature $\left(650{ }^{\circ} \mathrm{C}\right)$. The materials thus synthesized were tested as ECs in aqueous acid medium $\left(1 \mathrm{M} \mathrm{H}_{2} \mathrm{SO}_{4}\right)$ by cyclic voltammetry $(\mathrm{CV})$ and galvanostatic charge/discharge (GCD) methods. Different $\mathrm{KOH}$ to biochar mass ratios (from 0.3 to 3.6) were used to study its influence on texture, surface chemistry and electrochemical performance. We show that the upgrading of biochars derived from pine tannin pyrolysis as ECs electrodes is a viable alternative to their combustion for energy generation.

\section{Materials and methods}

\subsection{Synthesis of biochar-based activated carbons}

Biochar produced by fast pyrolysis of tannins from pine bark (Pinus radiata) in a bench-scale fluidized bed reactor at $550{ }^{\circ} \mathrm{C}[40,41]$ was used as activated carbon precursor and labelled as TBC (tannin biochar). Details on the pyrolysis process are given in [40]. Prior to activation, the TBC samples were crushed and sieved to a roughly unimodal distribution of particle sizes. The bulk density was estimated by filling containers of precisely known internal dimensions with the sieved fraction, and weighing the whole. The proximate analysis of $\mathrm{TBC}$, including moisture determination by heating at $100{ }^{\circ} \mathrm{C}$ for $2 \mathrm{~h}$, ash determination by heating at $550{ }^{\circ} \mathrm{C}$ for $14 \mathrm{~h}$, and volatiles by heating at $850{ }^{\circ} \mathrm{C}$ for $7 \mathrm{~min}$, was performed.

The TBC was mechanically mixed with $\mathrm{KOH}$ granules (Merck, $\geq 85 \%$ purity) by grinding in a mortar until a homogenous particle size was observed, then subjected to a thermal treatment at $650{ }^{\circ} \mathrm{C}$ for $1 \mathrm{~h}$, under a flow of $100 \mathrm{~mL} \mathrm{~min}^{-1}$ of $\mathrm{N}_{2}$ at a pressure of $1.38 \times 10^{5} \mathrm{~Pa}$, using 10 ${ }^{\circ} \mathrm{C} \min ^{-1}$ as the heating rate. The ACs were labelled as TBC-KAR, where AR is the activating ratio on a weight basis defined as the mass of $\mathrm{KOH}$ per gram of biochar. In the present work, 
ARs of $0.3,0.6,1.1,1.9,2.8$ and 3.6 were used. For comparison purposes, a sample was subjected to the same thermal treatment in the absence of activating agent (TBC-K0).

\subsection{Physicochemical characterization}

Nitrogen adsorption-desorption isotherms of biochar-derived ACs were measured at $-196{ }^{\circ} \mathrm{C}$ using an ASAP 2020 Micromeritics equipment, while carbon dioxide adsorption isotherms were obtained at $0{ }^{\circ} \mathrm{C}$ using an ASAP 2420 Micromeritics system. The Brunauer-EmmetTeller (BET) specific area $\left(A_{B E T}, \mathrm{~m}^{2} \mathrm{~g}^{-1}\right)$ was obtained from the nitrogen adsorption isotherms using Microactive ${ }^{\circledR}$ software (Micromeritics). The total volume of pores $\left(V_{0.97}, \mathrm{~cm}^{3} \mathrm{~g}^{-1}\right)$ was determined at a relative pressure $\left(P / P_{0}\right)$ of 0.97 , whereas the micropore volume was calculated by applying the Dubinin-Radushkevich (DR) equation to the data obtained from the $\mathrm{N}_{2}$ $\left(V_{D R, N_{2}}, \mathrm{~cm}^{3} \mathrm{~g}^{-1}\right)$ and $\mathrm{CO}_{2}$ isotherms $\left(V_{D R, C O_{2}}, \mathrm{~cm}^{3} \mathrm{~g}^{-1}\right)$. The mesopore volume $\left(V_{\text {meso }}, \mathrm{cm}^{3} \mathrm{~g}^{-}\right.$ ${ }^{1}$ ) was calculated as the difference $V_{0.97}-V_{D R, N_{2}}$. The 2D non-local density functional theory model for heterogeneous surface (2D-NLDFT-HS) was applied to $\mathrm{N}_{2}$ and $\mathrm{CO}_{2}$ adsorption isotherms to obtain the pore size distribution (PSD) and the following parameters: specific surface area $\left(S_{N L D F T}, \mathrm{~m}^{2} \mathrm{~g}^{-1}\right)$, total pore volume $\left(V_{N L D F T}, \mathrm{~cm}^{3} \mathrm{~g}^{-1}\right)$, micropore volume $\left(V_{\mu, N L D F T}\right.$, $\left.\mathrm{cm}^{3} \mathrm{~g}^{-1}\right)$, ultramicropore volume $\left(V_{u \mu, N L D F T}\right.$, pore size $\left.<0.7 \mathrm{~nm}\right)$, mesopore volume $\left(V_{\text {meso,NLDFT }}\right.$ $\left.=V_{N L D F T}-V_{\mu, N L D F T}\right)$. Finally, the average widths of pores $\left(w_{a v}\right)$, micropores $\left(w_{\mu, a v}\right)$, and ultramicropores $\left(w_{u \mu, a v}\right)$ were calculated according to Eq. 1:

$$
w_{a v}=\frac{\sum_{i=1}^{n}\left(\frac{d V}{d w}\right)_{i} w_{i}}{\sum_{i=1}^{n}\left(\frac{d V}{d w}\right)_{i}}
$$

considering the complete range of pore widths $w\left(w_{a v}\right)$, and up to $w=2 \mathrm{~nm}\left(w_{\mu, a v}\right)$ or $w=0.7$ $\mathrm{nm}\left(w_{u \mu, a v}\right)$, respectively. The 2D-NLDFT-HS method is more appropriate than the standard NLDFT slit-pore model for the analysis of real carbon materials with heterogeneous surfaces 
and it is free of common artefacts [42,43]. SAIEUS® software (Micromeritics) was used for data treatment applying the 2D-NLDFT-HS model.

Transmission electron microscopy (TEM) images were obtained with a Jeol ARM 200F electron microscope. X-ray photoelectron spectroscopy (XPS) spectra were recorded with an ESCAPlus OMICROM system using a non-monochromatized $\operatorname{MgK} \alpha$ X-ray source (1253.6 $\mathrm{eV}$ ) operating at $10 \mathrm{kV}$ and $15 \mathrm{~mA}$. Analyser pass energies of 50 and $20 \mathrm{eV}$ were used for survey scans and $\mathrm{C} 1 \mathrm{~s}$ and $\mathrm{O} 1 \mathrm{~s}$ high-resolution scans, respectively. Binding energies were referenced to the $\mathrm{C} 1 \mathrm{~s}$ peak $(284.5 \mathrm{eV})$. Shirley-type background subtraction, peak fitting and quantification were carried out using CASA data processing software. Elemental analysis $(\mathrm{C}$, $\mathrm{N}, \mathrm{S}, \mathrm{H}$ and $\mathrm{O}$ ) of the tannin-derived ACs was carried out using a Vario EL Cube analyser (Elementar).

Raman spectra were obtained with an XploRa Raman spectrometer (Horiba Scientific), from raw samples studied with a 50× long-range objective. A holographic grating of 1200 lines per $\mathrm{mm}$ was used with a circularly polarized laser of wavelength $532 \mathrm{~nm}$, filtered at $10 \%$ of its nominal power to avoid heating or damaging the samples. Each spectrum was obtained from an average of 3 to 5 measurements on different grains, accumulated twice for $120 \mathrm{~s}$ to $180 \mathrm{~s}$, between 800 and $2200 \mathrm{~cm}^{-1}$. A 5-band deconvolution, necessary to fit perfectly the spectra, was performed with the Labspec6 software from Horiba.

\subsection{Electrochemical characterization}

Electrochemical measurements were carried out with a Biologic VMP3 workstation using symmetrical two-electrode Swagelok-type cells. The electrodes $(5 \mathrm{~mm}$ in diameter) were prepared from a paste containing the ground AC materials, polytetrafluoroethylene (PTFE) binder (Aldrich, 60 wt.\% suspension in water) and carbon black, in a weight ratio of 85:10:5. Previously, the active materials were finely ground using a Retsch MM 400 mixer mill system. The total mass loading of the resultant electrodes was about $10.7 \mathrm{mg} \mathrm{cm}^{-2}(\sim 9 \mathrm{mg}$ 
$\mathrm{cm}^{-2}$ of effective carbon material), which is comparable to commercial standards (about 10 $\mathrm{mg} \mathrm{cm}{ }^{-2}$ ) [44-47]. Prior to electrochemical characterization, the carbon electrodes were impregnated for one week in the electrolyte, an aqueous solution of $1 \mathrm{M} \mathrm{H}_{2} \mathrm{SO}_{4}$ (Sigma Aldrich). The electrochemical capacitors were assembled using two carbon electrodes of comparable mass isolated by a porous quartz filter (Pall@, $9 \mathrm{~mm}$ diameter). Gold current collectors were used at both sides.

Electrochemical impedance spectroscopy (EIS) measurements were performed in alternating current at the open circuit potential (OCP) in the frequency range of $100 \mathrm{kHz}$ to $1 \mathrm{mHz}$ with a sinusoidal amplitude of $10 \mathrm{mV}$. The specific gravimetric capacitance of the cell from the EIS analysis $\left(C_{E I S}, \mathrm{~F} \mathrm{~g}^{-1}\right)$ was calculated according to Eq. 2:

$$
C_{E I S}=\frac{|\operatorname{Im}(Z)|}{4 \pi f m\left[(\operatorname{Im}(Z))^{2}+(\operatorname{Re}(Z))^{2}\right]}
$$

where $f(\mathrm{~Hz})$ is the frequency, $\operatorname{Im}(Z)$ and $\operatorname{Re}(Z)(\Omega)$ are the imaginary and real components of the impedance, and $m(\mathrm{~g})$ is the mass of the active material in the two electrodes. The normalized capacitances curves as a function of frequency were determined by considering the maximum specific capacitance, i.e., that obtained at the minimum frequency, $1 \mathrm{mHz}$ $\left(C_{E I S} / C_{E I S, I m H z}\right)$.

Cyclic voltammetry (CV) tests were carried out in the range $0-0.9 \mathrm{~V}$ at scan rates increasing from 5 to $100 \mathrm{mV} \mathrm{s}^{-1}$. The specific gravimetric capacitance of the cell $\left(C_{c e l l}, \mathrm{~F} \mathrm{~g}{ }^{-1}\right)$ was obtained from the area of the voltammograms using Eq. 3:

$$
C_{c e l l}=\frac{\oint I d V}{2 v m \Delta V}
$$

where $I(\mathrm{~A})$ is the current, $v\left(\mathrm{~V} \mathrm{~s}^{-1}\right)$ is the scan rate and $\Delta V(\mathrm{~V})$ is the potential. The electrode capacitance $\left(C_{e}, \mathrm{~F} \mathrm{~g}^{-1}\right)$ was estimated by Eq. 4 :

$$
C_{e}=4 C_{\text {cell }}
$$

Galvanostatic charge/discharge (GCD) cycling was also performed in the potential window between 0 and $0.9 \mathrm{~V}$ at current densities between 0.5 and $10 \mathrm{~A} \mathrm{~g}^{-1}$ (based on the active mass 
of a single electrode). The specific gravimetric capacitance of the cell from the GCD tests was determined by Eq. 5:

$$
C_{G C D}=\frac{I}{2 m \frac{d V}{d t}}
$$

where $\Delta t(\mathrm{~s})$ is the time of the discharge curve and $d V / d t\left(\mathrm{~V} \mathrm{~s}^{-1}\right)$ is the slope of the discharge curve after subtracting the potential drop $\left(I R_{d r o p}\right)$.

Ragone plots were obtained by calculating the specific energy $\left(E, \mathrm{~W} \mathrm{~h} \mathrm{~kg}^{-1}\right)$ and the specific power $\left(P, \mathrm{~W} \mathrm{~kg}^{-1}\right)$ using Eq. 6 and 7, respectively:

$$
\begin{aligned}
& E=\frac{1}{2} C_{G C D} V^{2} \\
& P=\frac{E}{t_{d}}
\end{aligned}
$$

where $V$ and $t_{\mathrm{d}}$ are respectively the operation voltage $\left(V_{\max }-I R_{d r o p}\right)$ and the discharge time after subtraction of the potential drop. For the determination of the specific energy, the specific

capacitance of the cell obtained from GCD cycling $\left(C_{G C D}\right)$ was considered.

Long-term stability was evaluated by charge-discharge cycling at $5 \mathrm{~A} \mathrm{~g}^{-1}$ over 10,000 cycles. Volumetric capacitances $\left(\mathrm{F} \mathrm{cm}^{-3}\right)$ were calculated from the packing density taking into account the geometric area and the average thickness of the electrode, which was determined using a Keyence LK-G32 non-contact sensor [48].

Self-discharge experiments were performed by monitoring the OCP decay for $24 \mathrm{~h}$. Previously, the cells were charged at a current density of $1 \mathrm{~A} \mathrm{~g} \mathrm{~g}^{-1}$ and stabilized at $0.9 \mathrm{~V}$ for 1 $\mathrm{h}$ in order to minimize the charge redistribution effect [49]. Leakage currents were recorded at

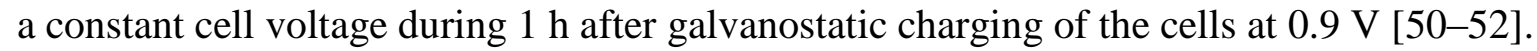

$\mathrm{CV}$ tests were also performed in a three-electrode electrochemical cell to better understand the pseudocapacitance contribution of biochar-derived ACs. A graphite rod was used as a counter electrode and a reversible hydrogen electrode (RHE) inside a Luggin capillary as reference. 
Prior to electrochemical measurements, the carbon electrodes $\left(5 \mathrm{~mm}\right.$ in diameter, $\sim 9 \mathrm{mg} \mathrm{\textrm {cm } ^ { - 2 }}$ of effective carbon material) were pressed to 5 tons on a titanium gauze (Alfa Aesar ${ }^{\mathrm{TM}}$ ). The resultant working electrodes were impregnated for one week in the electrolyte, an aqueous solution of $1 \mathrm{M} \mathrm{H}_{2} \mathrm{SO}_{4}$ (Sigma Aldrich). The specific gravimetric capacitance of the electrode obtained by $\mathrm{CV}$ tests in a three-electrode system was calculated by Eq. 3 considering the mass of the effective material in the working electrode.

\section{Results and discussion}

\subsection{Characteristics of the tannin-derived biochar}

Figure S1a (Supporting Information) shows the particle size distribution, centered on approximately $75 \mu \mathrm{m}$, obtained after crushing and sieving the TBC sample, prior to activation with $\mathrm{KOH}$. From the data shown in Figure S1b, the bulk density of the biochar powder was found to be $0.582 \pm 0.005 \mathrm{~g} \mathrm{~mL}^{-1}$. The proximate analysis led to a content of fixed carbon of $72.95 \pm 0.5 \%$ (on dry basis), a content of volatile matter of $24.21 \pm 0.4 \%$, and a low amount of ashes $(2.84 \pm 0.02 \%)$.

\subsection{Textural properties}

The $\mathrm{N}_{2}$ adsorption-desorption isotherms of the ACs prepared from the pine tannin-derived biochar are given in Figure 1a, while the corresponding textural properties are listed in Table S1. All carbons, including non-activated biochar (TBC), exhibit type I isotherms with an almost horizontal plateau at $P / P_{0}>0.1$, indicating that the porosity is mainly associated with micropores. The sample only pyrolyzed at $550{ }^{\circ} \mathrm{C}(\mathrm{TBC})$ showed limited development of porosity $\left(A_{B E T}=384 \mathrm{~m}^{2} \mathrm{~g}^{-1} ; S_{N L D F T}=623 \mathrm{~m}^{2} \mathrm{~g}^{-1} ; V_{0.97}=0.17 \mathrm{~cm}^{3} \mathrm{~g}^{-1}\right)$. As the AR increases, a progressive enhancement in adsorption capacity is observed, leading to high values of specific surface area $\left(A_{B E T}=2554 \mathrm{~m}^{2} \mathrm{~g}^{-1}\right.$ and $\left.S_{N L D F T}=2147 \mathrm{~m}^{2} \mathrm{~g}^{-1}\right)$ and total pore volume $\left(V_{0.97}=1.10\right.$ $\mathrm{cm}^{3} \mathrm{~g}^{-1}$ ) for the sample activated at the highest AR (TBC-K3.6). These values are higher than 
those reported by other authors for ACs obtained by $\mathrm{KOH}$ activation of biomass precursors at temperatures above $650{ }^{\circ} \mathrm{C}$, such as human hair $\left(1306 \mathrm{~m}^{2} \mathrm{~g}^{-1}\right)$ [13], hydrolysed lignin (1660 $\left.\mathrm{m}^{2} \mathrm{~g}^{-1}\right)$ [19], broad beans $\left(655 \mathrm{~m}^{2} \mathrm{~g}^{-1}\right)$ [53], coffee endocarp $\left(893 \mathrm{~m}^{2} \mathrm{~g}^{-1}\right)$ [54] or ginkgo shells $\left(1775 \mathrm{~m}^{2} \mathrm{~g}^{-1}\right)$ [55]. Such a well-developed texture results from both chemical activation by carbon oxidation and carbon lattice expansion by intercalation of potassium, according to Eq. $8[7,15,16,56-58]:$

$$
6 \mathrm{KOH}+2 \mathrm{C} \rightarrow 2 \mathrm{~K}+3 \mathrm{H}_{2}+2 \mathrm{~K}_{2} \mathrm{CO}_{3}
$$

This progressive activation also leads to a lower product yield for materials activated at the highest AR, as can be seen in Table S1, ranging from $33 \%$ for the non-activated carbon (TBC-K0) to $21 \%$ for TBC-K3.6.

Similarly, a gradual widening of the "knee" of the isotherms at low $P / P_{0}$ is evident with the increase in AR, indicating a broadening of the micropore size [59], as can be seen in Table S1 and Figure S2a of the Supporting Information. In addition, the materials with a high degree of activation, i.e., those obtained using an AR of 2.8 and 3.6, exhibited a slightly higher slope in the multilayer region due to the generation of narrow mesopores by $\mathrm{KOH}$ activation and micropore merging.

Micropore widening is also observed in the $\mathrm{CO}_{2}$ isotherms (Figure 1b), where the slope at $\mathrm{P} / \mathrm{P}_{0}>0.01$ clearly increases at $\mathrm{AR}$ above 1.1. Conversely, a lower $\mathrm{CO}_{2}$ adsorption was evidenced for ACs prepared with the highest AR, such as TBC-K2.8 and TBC-K3.6, at P/ $\mathrm{P}_{0}$ $<0.005$. In line with these results, a lower contribution of ultramicropores is evident for the most activated materials, indicating a significant loss of pores of width $w<0.7 \mathrm{~nm}$, with the consequent increase of supermicropores $(0.7 \mathrm{~nm}<w<2 \mathrm{~nm})$ and mesopores, due to pore widening by $\mathrm{KOH}$ activation at high AR (Figure S2b). Pore size is a key parameter in the design of efficient ECs, since pores that are too small are not easily impregnated by the electrolyte, and therefore these pores do not efficiently contribute to the double-layer 
capacitance $[3,60]$, whereas faster ion transport through wider micropores or mesopores results in higher rate capability $[61,62]$.
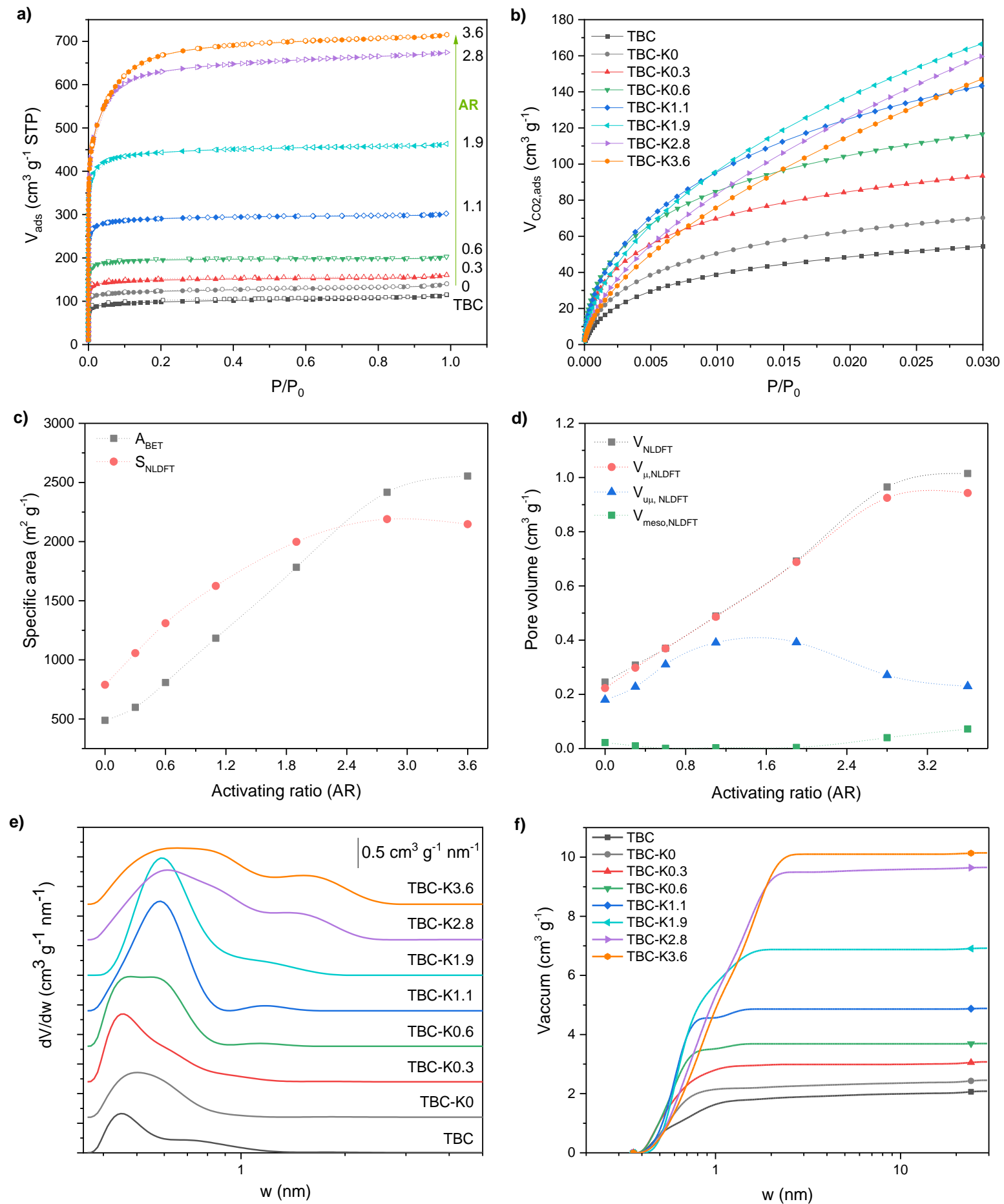

Figure 1. (a) $\mathrm{N}_{2}$ adsorption-desorption isotherms at $-196^{\circ} \mathrm{C}$; (b) $\mathrm{CO}_{2}$ isotherms at $0^{\circ} \mathrm{C}$; (c) specific areas determined by BET and NLDFT methods as a function of the activating ratio (AR); (d) variation of the pore volumes (total, micropores, ultramicropores and mesopores) 
obtained by the NLDFT method when combining both $\mathrm{N}_{2}$ and $\mathrm{CO}_{2}$ adsorption data; (e) PSD determined by applying the NLDFT method on both $\mathrm{N}_{2}$ and $\mathrm{CO}_{2}$ isotherms; (f) cumulative pore volume as a function of the average pore width of biochar-derived ACs. Dotted curves are just guides for the eye.

Figure 1c shows $A_{B E T}$ and $S_{N L D F T}$ as a function of the activating ratio. Values of $A_{B E T}$ are lower than those of $S_{N L D F T}$ for AR $<2.8$. This is because the BET method assumes monolayer adsorption on each pore wall. It therefore underestimates the surface area of narrow micropores where only one layer is adsorbed between the two walls, and hence only one wall is considered [63]. The latter is in good agreement with the high contribution of ultramicropores (around 56 - $84 \%$, Figure S2b) determined for the pristine carbon (TBC) and activated materials with $\mathrm{AR}<2.8$. Conversely, the values of $A_{B E T}$ are lower than those of $S_{N L D F T}$ for the most activated carbons (TBC-K2.8 and TBC-K3.6) due to multilayer adsorption in the wider pores [59,63-65]. The 2D-NLDFT-HS model combining $\mathrm{N}_{2}$ and $\mathrm{CO}_{2}$ adsorption data is known to provide a more accurate estimate of the textural parameters of ACs $[27,42,66]$. Correct interpretation of these properties will allow a better correlation between textural characteristics and the electrochemical capacitance [67]. A maximum $S_{N L D F T}$ of 2190 $\mathrm{m}^{2} \mathrm{~g}^{-1}$ (Table S1) was obtained for TBC-K2.8, while a higher KOH amount did not result in a significant change in texture (Figure 1c).

Figure 1d shows the ultramicropore, micropore and mesopore volumes obtained by the 2DNLDFT-HS method as a function of AR. As can be seen, the main contribution to the total volume is the microporosity $\left(V_{N L D F T} \approx V_{\mu, N L D F T}\right)$, and activation resulted in a progressive increase in micropore volume. A decrease in $V_{u \mu, N L D F T}$ and a slight increase in $V_{m e s o, N L D F T}$ are observed for AR higher than 1.9 due to pore widening by $\mathrm{KOH}$ activation. The micropore volume obtained by the Dubinin-Radushkevich method from the $\mathrm{N}_{2}\left(V_{D R, N_{2}}\right)$ or $\mathrm{CO}_{2}\left(V_{D R, C O_{2}}\right)$ 
isotherms are also given for comparison in Table $\mathrm{S} 1$ (SI). $V_{D R, N_{2}}$ and $V_{D R, C O_{2}}$ exhibit a similar trend to those determined by NLDFT for the microporous and ultramicroporous range, respectively (see Table $\mathrm{S} 1$ ).

The widening of pores with increasing AR is also confirmed by the PSD calculated by the 2D-NLDFT-HS method (Figure 1e), which reveals a shift to larger pore sizes as the activation degree increases. In the micropore range, a bimodal distribution is observed for activated samples. The main maximum shifts from 0.51 to $0.67 \mathrm{~nm}$ as the AR increases from 0.6 to 3.6 , whereas the second pore peak is shifted from 1.1 to $1.6 \mathrm{~nm}$. This second contribution to larger micropores ( 1 to $2 \mathrm{~nm}$ ) is more evident for $\mathrm{AR} \geq 1.9$. In addition, TBCK2.8 and TBC-K3.6 show a continuous PSD over the entire range of micropores, which can promote ion diffusion through the interconnected pores and thus improve the electrochemical performance of ECs [68]. On the contrary, a low contribution of pores $>1 \mathrm{~nm}$ in size is observed in the PSD of non-activated or materials activated at AR below 1.9. Finally, a higher cumulative pore volume was obtained as the activating ratio increased, as can be seen in

\section{Figure 1f.}

\subsection{Chemical composition and morphology}

The bulk and surface chemical composition of the tannin-derived carbons was studied by elemental analysis (EA) and XPS, respectively (Table S2, supplementary information). The biochar prepared at $550{ }^{\circ} \mathrm{C}(\mathrm{TBC})$ has a high bulk oxygen content $(14.8 \mathrm{wt} . \%)$ in agreement with the phenolic nature of the tannin precursor. Oxygen-containing groups were largely eliminated during the thermal treatment at $650{ }^{\circ} \mathrm{C}$ in the absence of $\mathrm{KOH}$, as suggested by the drastic reduction in the amount of surface $\mathrm{O}$ for $\mathrm{TBC}-\mathrm{K} 0\left(\mathrm{O}_{\mathrm{EA}}=7.7 \mathrm{wt} . \%\right)$. In contrast, activated biochars presented a high bulk oxygen content of 14 - 23 wt.\% due to the insertion of oxygen atoms during $\mathrm{KOH}$ activation at $650{ }^{\circ} \mathrm{C}$ (Figure 2a). 
In general, the XPS analysis showed lower values of oxygen on the surface of activated biochars (about 10-15 wt.\%), suggesting an enrichment of the bulk in oxygen species. The ratio $\mathrm{O}_{\mathrm{XPS}} / \mathrm{O}_{\mathrm{EA}}$ was calculated as a measure of the distribution of oxygen functional groups, i.e., a higher ratio means an enhancement of oxygen on the surface. The sample activated with a ratio of 2.8 presented the lowest value $(0.48)$ but the largest $S_{N L D F T}\left(2190 \mathrm{~m}^{2} \mathrm{~g}^{-1}\right)$ of the samples studied in this work, suggesting that oxygen is mainly found in the bulk of the material.

The amounts of oxygen in the bulk $\left(\mathrm{O}_{\mathrm{EA}}\right)$ and on the surface $\left(\mathrm{O}_{\mathrm{XPS}}\right)$, normalized in terms of specific area determined by the BET and NLDFT methods at different ARs, are plotted in Figure 2b. The samples with the most developed porosities (TBC-K2.8 and K-3.6) presented a lower normalized oxygen content, both in the bulk and on the surface of the materials, which is ascribed to their developed porosities. Consequently, higher $\mathrm{C} / \mathrm{O}$ atomic ratios were obtained for these materials compared to activated biochars at $\mathrm{AR}<1.9$. Obviously, and although less accurate as explained above, similar trends were obtained considering the specific areas obtained by the BET method $\left(A_{B E T}\right)$. In other words, at low AR, the high oxygen content and less developed porosity are consistent with the higher product yields (27 $30 \%$, Table S1) or activation yields $(61-74 \%)$ observed for activated biochars prepared at $\mathrm{AR}<2.8$.

In addition, a low nitrogen content was also determined by EA for all samples (Table S2), which is ascribed to amino acids leached with polyphenols during the tannin extraction step, whereas surface nitrogen was not detected by XPS.

The nature of the oxygen species was estimated by deconvolution of the high-resolution XPS spectra of C1s and O1s (Table S3, supplementary information). Figure 2c and 2d show the relative atomic $\mathrm{C} 1 \mathrm{~s}$ and $\mathrm{O} 1 \mathrm{~s}$ contributions as a function of $\mathrm{AR}$, respectively. $\mathrm{KOH}$ activation resulted in the introduction of oxygen species at the carbon surface compared to pristine 
biochar (TBC) or heat-treated carbon in the absence of $\mathrm{KOH}$ (TBC-K0) as evidenced by: (i) the decrease in the relative content of $\mathrm{C}-\mathrm{C}$ single bonds in hydrocarbons, aromatics and aliphatic groups (peak CI) and (ii) the increase in the contribution of oxygen-containing groups (peaks CII, CIII and CIV) (Figure 2c).
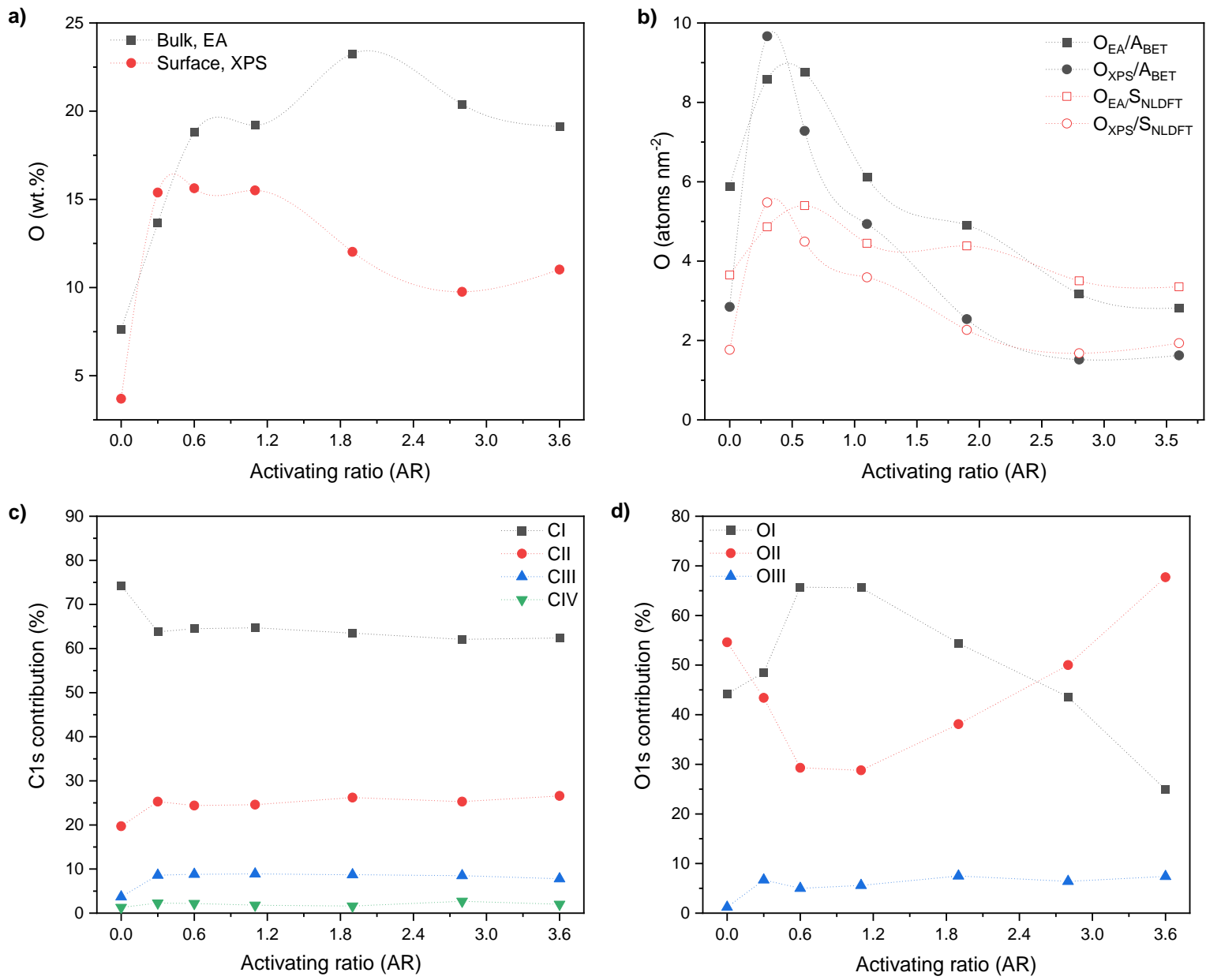

Figure 2. (a) Bulk and surface oxygen content (wt.\%) obtained by elemental analysis (EA) and XPS, respectively; (b) atomic oxygen obtained by EA and XPS and normalized with respect to specific area determined by BET and NLDFT methods as a function of the activating ratio (AR); (c) relative atomic $\mathrm{C} 1 \mathrm{~s}$ and (d) O1s contributions from XPS of biocharderived ACs at different ARs. Dotted curves are just guides for the eye.

Regarding the nature of $\mathrm{O}$ moieties (Figure 2d), the raw biochar (TBC) and the sample thermally treated at $650{ }^{\circ} \mathrm{C}(\mathrm{TBC}-\mathrm{K} 0)$ present $\mathrm{OII}$ as the major contribution (55-60\%), which 
is mainly associated with phenolic groups in agreement with the chemical nature of the carbon precursor: tannin. Carbonyl and quinone functionalities (OI: 40-44\%) are the second most common groups, followed by carboxyl groups (OIII). Carbonyl and quinone (OI) groups are known to increase reversible redox reactions (especially in aqueous media), which increase the capacitance of the EC by pseudocapacitive effects $[15,69,70]$. Moreover, basic groups (OI and OII) can improve the wettability of the material by the electrolyte, increasing the available surface area and hence improving the electrochemical performance $[15,70]$. In contrast, OIII species with high polarity and acidic nature (such as carboxylic groups) may reduce ion mobility, thus increasing the resistance $[15,70,71]$. Chemical activation produced an increase in the OI contribution while the relative amount of OII decreased to ARs of 1.1, indicating the generation of electrochemically active groups (carbonyl and quinone) as the main functionalities. A higher amount of $\mathrm{KOH}(\mathrm{AR}>1.1)$ resulted in an inverse trend, i.e., the contribution of OI gradually decreased and that of OII increased. Indeed, phenolic species were again in majority for the most activated materials (TBC-K2.8 and TBC-K3.6). The OIII contribution slightly increased after $\mathrm{KOH}$ activation and remained constant with AR (5.0-7.5 wt.\%).

These results suggest differences in the oxidation mechanisms of the carbon surface during activation as a function of AR. The formation of elemental $\mathrm{K}$ and $\mathrm{K}_{2} \mathrm{CO}_{3}$ according to $\mathbf{E q .} 8$ is well-known to be promoted at high $\operatorname{AR}[7,15,16,56]$. In addition, it has been reported earlier [57,58] that, in addition to Eq. 8, the thermal decomposition of $\mathrm{KOH}$ can lead to the selective formation of steam according to Eq. 9, which leads to the physical activation of the biochar and, consequently, to different O-containing functionalities:

$$
2 \mathrm{KOH} \rightarrow \mathrm{K}_{2} \mathrm{O}+\mathrm{H}_{2} \mathrm{O}
$$

On the other hand, TEM images (Figure 3a) show the disordered structure of biochar-derived ACs, consisting of randomly oriented pores. A homogeneous distribution of oxygen in the 
carbon matrix was evidenced by EDX (Figure 3a). Chemical activation did not alter the morphology of the resultant materials, as shown in Figure $\mathbf{3 b}$ for the sample simply pyrolyzed (TBC) and in Figure 3c and 3d for materials obtained using ARs of 1.1 (TBCK1.1) and 3.6 (TBC-K3.6).
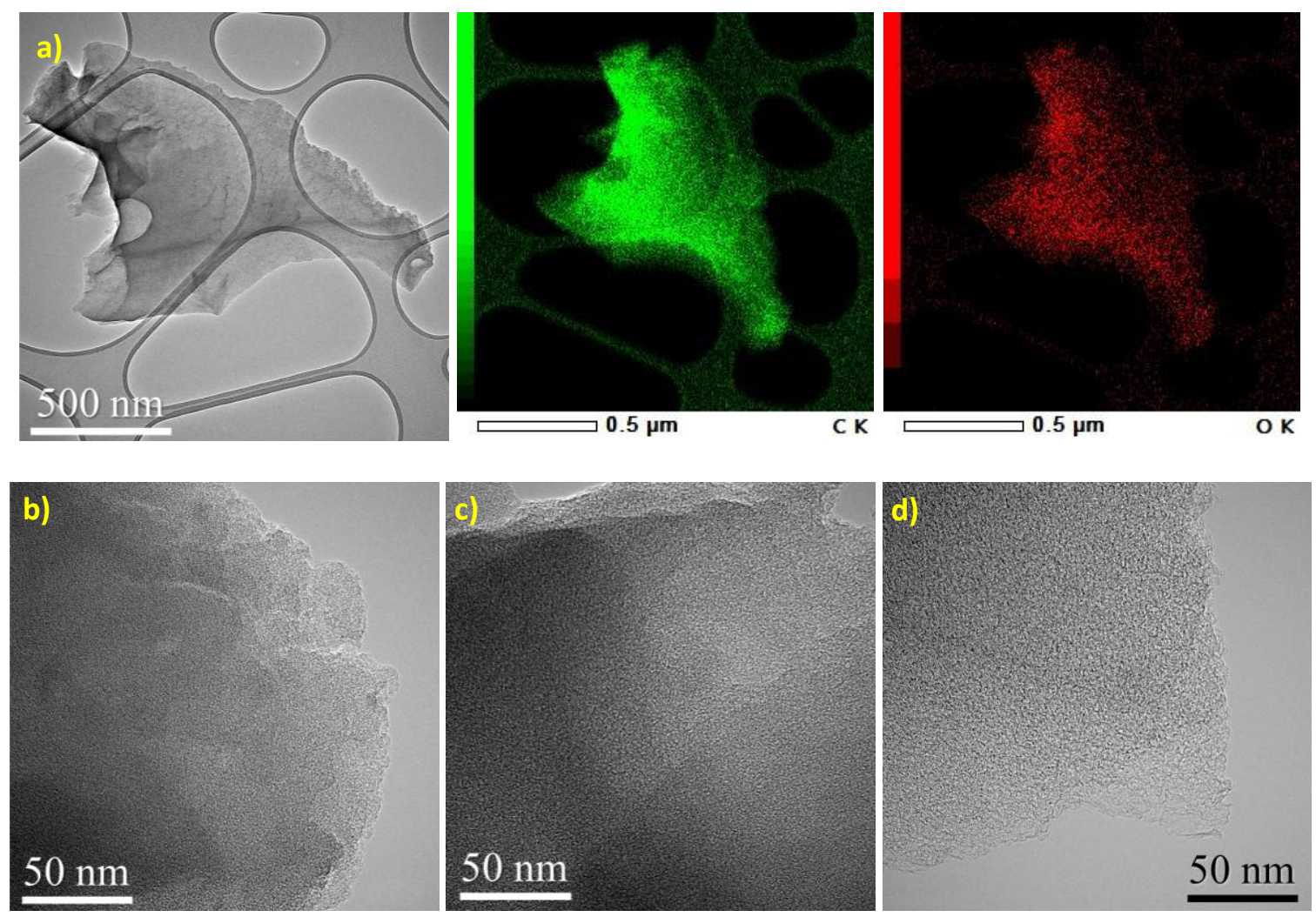

Figure 3. (a) TEM image of TBC-K1.1 and corresponding chemical mapping of $\mathrm{C}$ and $\mathrm{O}$; and TEM images of (b) TBC, (c) TBC-K1.1 and (d) TBC-K3.6.

\subsection{Electrochemical performance}

The electrochemical behaviour of the activated biochars was studied in aqueous acid medium (1 $\mathrm{M} \mathrm{H}_{2} \mathrm{SO}_{4}$ ) by $\mathrm{CV}$ under standard commercial mass loadings. The capacitance-voltage curves of the cells obtained at $5 \mathrm{mV} \mathrm{s}^{-1}$ for the TBC-derived ECs are given in Figure 4a. The ACs present a double-layer capacitive behaviour with quasi-rectangular CV curves at low scan rates. The values of specific cell capacitance $\left(C_{\text {cell }}, \mathrm{F} \mathrm{g}^{-1}\right)$ determined by $\mathrm{CV}$ are plotted in Figure 4b as a function of AR. An increase in cell specific capacitance was observed when 
AR increases due to the development of porosity by $\mathrm{KOH}$ activation. A maximum cell capacitance $\left(C_{\text {cell }}\right)$ of approximately $60 \mathrm{~F} \mathrm{~g}^{-1}$, and thus an electrode capacitance of approximately $240 \mathrm{~F} \mathrm{~g}^{-1}\left(C_{e}=4 C_{c e l l}\right)$, was found for the sample activated using an AR of 2.8 , which gave the highest $S_{N L D F T}$. Indeed, a clear linear correlation between $C_{c e l l}$ and $S_{N L D F T}$ was found with a determination coefficient $\left(\mathrm{R}^{2}\right)$ of 0.996 at $5 \mathrm{mV} \mathrm{s}^{-1}$ (Figure $\mathbf{4 b}$, inset). A lower determination coefficient (0.915) was obtained when considering $A_{B E T}$ instead of $S_{N L D F T}$, illustrating a better fit of the 2D-NLDFT-HS model for the correlation of the capacitance and textural properties of biochar-derived ACs. Divergences to linearity in the capacitance- $A_{B E T}$ relationship have been previously pointed out by other authors [72].
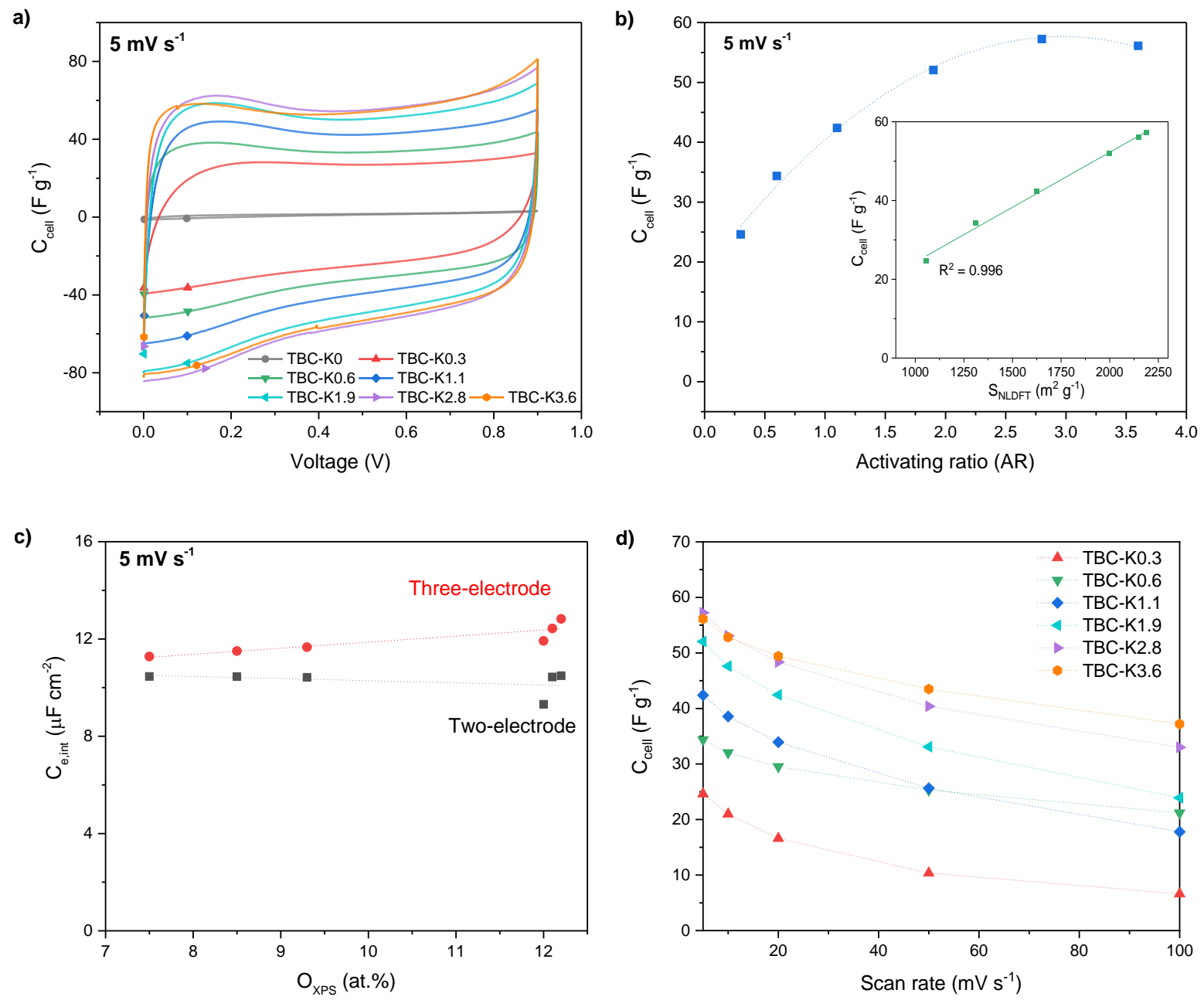

Figure 4. Results from $\mathrm{CV}$ of biochar-derived $\mathrm{ACs}$ in aqueous $1 \mathrm{M} \mathrm{H}_{2} \mathrm{SO}_{4}$ : (a) curves of cell capacitance vs. voltage at $5 \mathrm{mV} \mathrm{s}^{-1}$ obtained in symmetrical ECs; (b) cell capacitance obtained 
in symmetrical ECs as a function of activating ratio (AR) and as a function of specific surface area determined by $2 \mathrm{D}-\mathrm{NLDFT}-\mathrm{HS}$ method $\left(S_{N L D F T}\right.$, see inset) at $5 \mathrm{mV} \mathrm{s}^{-1}$; (c) electrode capacitance obtained in symmetrical ECs (two-electrode configuration, grey dots) and in a three-electrode cell (red dots) normalized by $S_{N L D F T}\left(C_{\mathrm{e}, \text { int }}\right)$ as a function of atomic surface percentages of oxygen $\left(\mathrm{O}_{\mathrm{XPS}}\right)$ at $5 \mathrm{mV} \mathrm{s}^{-1}$; (d) cell capacitance vs. scan rate obtained in symmetrical ECs. Dotted curves are just guides for the eye.

In order to match the electrochemical storage behaviour to the surface chemistry, the capacitances of an electrode normalized by the $S_{N L D F T}$ surface area, called $C_{\mathrm{e}, \text { int }}$, were represented as a function of the atomic oxygen content determined by XPS ( $\left.\mathrm{O}_{\mathrm{XPS}}\right)$ (Figure 4c). Capacitances obtained at a low scan rate $\left(5 \mathrm{mV} \mathrm{s}^{-1}\right)$ were considered in order to avoid the appearance of uncompleted redox reactions (due to kinetics limitations at fast sweep rates), which would underestimate the pseudocapacitance. Normalized electrode capacitances at 5 $\mathrm{mV} \mathrm{s}^{-1}$ present a value of $\sim 10.3 \mu \mathrm{F} \mathrm{cm}^{-2}$ (with an average of $13 \mu \mathrm{F} \mathrm{cm}^{-2}$ for $A_{\mathrm{BET}^{-} \text {-normalized }}$ capacitances). These values are comparable to or higher than those reported for other carbons in aqueous $\mathrm{H}_{2} \mathrm{SO}_{4}$ electrolyte, such as corn straw-based $\mathrm{AC}\left(\sim 9.3 \mu \mathrm{F} \mathrm{cm}{ }^{-2}\right)$ [21], tanninderived carbons $\left(\sim 8.6 \mu \mathrm{F} \mathrm{cm}^{-2}\right)[33]$ or hierarchically structured activated carbon $(\sim 8.0 \mu \mathrm{F}$ $\mathrm{cm}^{-2}$ ) [73], highlighting the great potential of ACs produced from pine bark biochars for energy storage. An increase in the surface oxygen content from 7.5 to 12.2 at.\% did not affect the interfacial capacitance of the electrode, even at the low scan rate of $5 \mathrm{mV} \mathrm{s}^{-1}$. This finding suggests a similar pseudocapacitive contribution of $\mathrm{KOH}$-activated electrodes obtained at different AR with a preferential double-layer storage mechanism [28]. Although twoelectrode configurations are useful to study the performance of the materials in conditions closer to those of real capacitors, electrochemical measurements in three-electrode cells provide a better estimate of the pseudocapacitive behaviour. CV tests in a conventional three- 
electrode system provided a better understanding of the effect of the surface chemistry on the capacitance of biochar-derived ACs. Figure S3a shows the capacitance-potential curves at 5 $\mathrm{mV} \mathrm{s}^{-1}$ of carbons obtained at different AR. In all the cases, a redox couple appeared at $0.5 \mathrm{~V}$ vs. RHE, which is ascribed to Faradaic reactions of carbonyl and quinone groups accounting for pseudocapacitance [74]. Interfacial capacitances obtained in a three-electrode configuration at $5 \mathrm{mV} \mathrm{s}^{-1}$ presented a value around $11.9 \mu \mathrm{F} \mathrm{cm}^{-2}$ (see Figure $4 \mathbf{c}$, red dots), which correlates well to that obtained in a two-electrode device $\left(10.3 \mu \mathrm{F} \mathrm{cm}{ }^{-2}\right)$. Additionally, an increase in atomic oxygen content led to an enhancement of the interfacial capacitance, evidencing a certain pseudocapacitive behaviour of the materials. However, the slight slope indicates that double-layer formation is the main storage mechanism in good correlation with the findings obtained in a symmetric two-electrode system. A linear relationship of $C_{e, \text { int }}$ measured in a three-electrode cell and the surface density of oxygen and nitrogen relative to carbon, $((\mathrm{O}+\mathrm{N}) / \mathrm{C}) / S_{N L D F T}\left(\mathrm{wt} . \% \mathrm{~g} \mathrm{~m}^{-2}\right)[64,75]$ was also found (Figure S3b). The fit of the data resulted in the following correlation (Eq. 10, with a determination coefficient of 0.751):

$$
C_{e, \text { int }}\left(F m^{-2}\right)=\frac{C_{e}}{S_{N L D F T}}=(0.094 \pm 0.007)+(1.767 \pm 0.509)\left|\frac{\left(\frac{O+N}{C}\right)}{S_{N L D F T}}\right|
$$

From the slope in Figure S3b, given by the coefficient of the second term of Eq. 10, the pseudocapacitance effect of ACs was estimated by considering a factor of $1.77 \mathrm{~F}$ per $\%$ of the ratio $(\mathrm{O}+\mathrm{N}) / \mathrm{C}$ per $\mathrm{m}^{2}$. Carbons obtained using low $A R$ presented a more significant pseudocapacitance, with a contribution ranging from $\sim 25 \%$ for poorly activated carbons to $\sim 17 \%$ for TBC-K2.8 and TBC-K3.6 (see inset in Figure S3b). The lower pseudocapacitance of the latter materials is ascribed to the loss of surface oxygen species (as evidenced by the lower $\mathrm{O}_{\mathrm{XPS}}$, see Table S2) during $\mathrm{KOH}$ activation at high $\mathrm{AR}$, and the decrease in the relative content of carbonyl and quinone groups (OI, Figure 2d), which are electrochemically active. The impact of scan rate on the capacitance was also evaluated by CV in symmetrical ECs. Figure S4 (supplementary information) exhibited quasi-rectangular shapes of the current 
density-voltage curves for TBC-K2.8 and TBC-K3.6 as the scan rate increases. This shows the rapid formation of the double layer for the most activated materials, which is consistent with their lower pseudocapacitance contribution. More importantly, the aforementioned materials retain about $62 \%$ of the initial cell capacitance when the scan rate increases from 5 to $100 \mathrm{mV} \mathrm{s}^{-1}$ (Figure 4d). The lower decrease of capacitance at high AR is explained by: i) the existence a well-connected porosity (see Figure 1e), where wider micropores facilitate the transport of the electrolyte ions to the micropores and; ii) an improved electrical conductivity due to the lower density of oxygen species, evidenced by the lower oxygen amount per surface area of highly activated materials (Figure $\mathbf{2 b}$ ) and the higher $\mathrm{C} / \mathrm{O}$ atomic ratio, which facilitates electron mobility to the carbon matrix. Carbon materials produced at AR $<2.8$ presented a sharper loss of capacitance, except for TBC-K0.6 with a relatively high retention of $61 \%$, comparable to that of the most activated materials. This material is a particular case where $\mathrm{KOH}$ activation resulted in a specific cell capacitance at high scan rates higher than, or comparable to, those of materials activated using 1.1 and $1.9 \mathrm{~g} \mathrm{KOH}$ per $\mathrm{g}$ of biochar, respectively, despite the larger $S_{N L D F T}$ of the latter samples. However, this larger surface area originated from the creation of ultramicropores, as evidenced by the largest values of $V_{u \mu, N L D F T}$ for TBC-K1.1 and TBC-K1.9 $\left(0.39 \mathrm{~cm}^{3} \mathrm{~g}^{-1}\right)$ vs. TBC-K0.6 $\left(0.31 \mathrm{~cm}^{3} \mathrm{~g}^{-1}\right)$. In addition, TBC-K0.6, TBC-K1.1 and TBC-K1.9 have a PSD with a main peak centred on 0.51 $-0.58 \mathrm{~nm}$, but the main difference is the higher mean pore width for the former material $(0.29$ vs 0.25 or $0.26 \mathrm{~nm}$, respectively), which may reduce ion electrolyte resistance. Finally, TBCK1.1 exhibited the lowest average pore diameter (and micropore diameter), which may produce the distortion of solvated ions, reducing the distance to the carbon surface, and as a result, this material exhibits a faster capability.

Figure S5 (supplementary information) shows the specific $\left(\mathrm{F} \mathrm{g}^{-1}\right)$ and volumetric $\left(\mathrm{F} \mathrm{cm}^{-3}\right)$ electrode capacitances as a function of scan rate. These values were determined considering 
the packing density $\left(\mathrm{g} \mathrm{cm}^{-3}\right)$, defined as the amount of active material per electrode volume [48]. The electrode volume was easily calculated by using the geometrical area and thickness of the electrodes. The materials with the highest porosity (TBC-K2.8 and TBC-K3.6) achieved the lowest packing densities $\left(0.30\right.$ and $0.33 \mathrm{~g} \mathrm{~cm}^{-3}$, respectively), whereas a value of about $0.4-0.42 \mathrm{~g} \mathrm{~cm}^{-3}$ was found for the rest of materials. Despite these differences, the volumetric capacitance $\left(\mathrm{F} \mathrm{cm}^{-3}\right)$ exhibited similar behaviour to that observed for the gravimetric capacitance $\left(\mathrm{F} \mathrm{g}^{-1}\right)$. In conclusion, the ECs based on the materials with the most developed texture (AR of 2.8 and 3.6) showed the highest capacitances at faster scan rates (see Figure 4 and Figure S5).

The ability of ions to penetrate the porous structure of the electrodes at different frequencies was studied by EIS by applying an alternating current with an amplitude of $10 \mathrm{mV}$ at OCP. The Nyquist plots of activated biochars in Figure 5a show a well-defined semicircle in the high-frequency range, followed by a $45^{\circ}$ Warburg region typical of porous carbons, and a nearly vertical line at low frequency $[76,77]$. Close inspection reveals a large Warburg region for the poorly activated material TBC-K0.3, indicating a substantial limitation of ion transport within the porous structure (diffuse layer resistance) [76]. As AR increases, the Warburg region is less evident, reaching values of $\sim 0.7 \Omega \mathrm{cm}^{2}$ for TBC-K2.8 and TBC-K3.6 due to the more developed porosity and enlarged pore size (Figure 5a, inset). These electrodes also exhibited the lowest internal resistances $\left(0.23\right.$ and $0.38 \Omega \mathrm{cm}^{2}$, respectively), as evidenced by the lower diameter of the semicircles in Figure 5a. These results suggest an improved electron transport in TBC-K2.8 and TBC-K3.6 electrodes, which may be related to the removal of oxygen species from the carbon surface when large amounts of $\mathrm{KOH}$ were used for activation, but also to the increase in the structural order when increasing AR, as shown by Raman spectroscopy in Fig S6. As expected from the nature of the carbon precursors and their preparation and post-processing conditions, all samples exhibited the typical spectra of highly 
disordered carbon, where the D1 band is more intense than the G band [78-81]. Due to the phenolic nature of tannin, all these materials are non-graphitizable and are in the carbonization regime under the present experimental conditions, for which an increase in the ratio of the intensities of the D1 and G bands, indicates an increase in crystallite size and thus an enhancement of the long-range order in carbon [82].

Normalized capacitances $\left(C_{E I S} / C_{E I S, 1 \mathrm{mHz}},\right)$ as a function of frequency are plotted in Figure $\mathbf{5} \mathbf{b}$. The relaxation time constant $\left(\tau_{0.5}=1 / f_{0.5}\right)$, i.e., the time required to discharge $50 \%$ of the saturation capacitance, decreases from 30 to $8 \mathrm{~s}$ with the increase of AR from 0.6 to 3.6. The faster performance of TBC-K2.8 $\left(\tau_{0.5}=8.5 \mathrm{~s}\right)$ and TBC-K3.6 $\left(\tau_{0.5}=8.3 \mathrm{~s}\right)$ is consistent with their larger micropore sizes (1.02 and $1.09 \mathrm{~nm}$, respectively) and adequate electron transport (see inset in Figure 5b). These relaxation times are lower than those obtained for commercial activated carbons $(\sim 10 \mathrm{~s})$, showing the applicability of the materials in realistic devices [83].
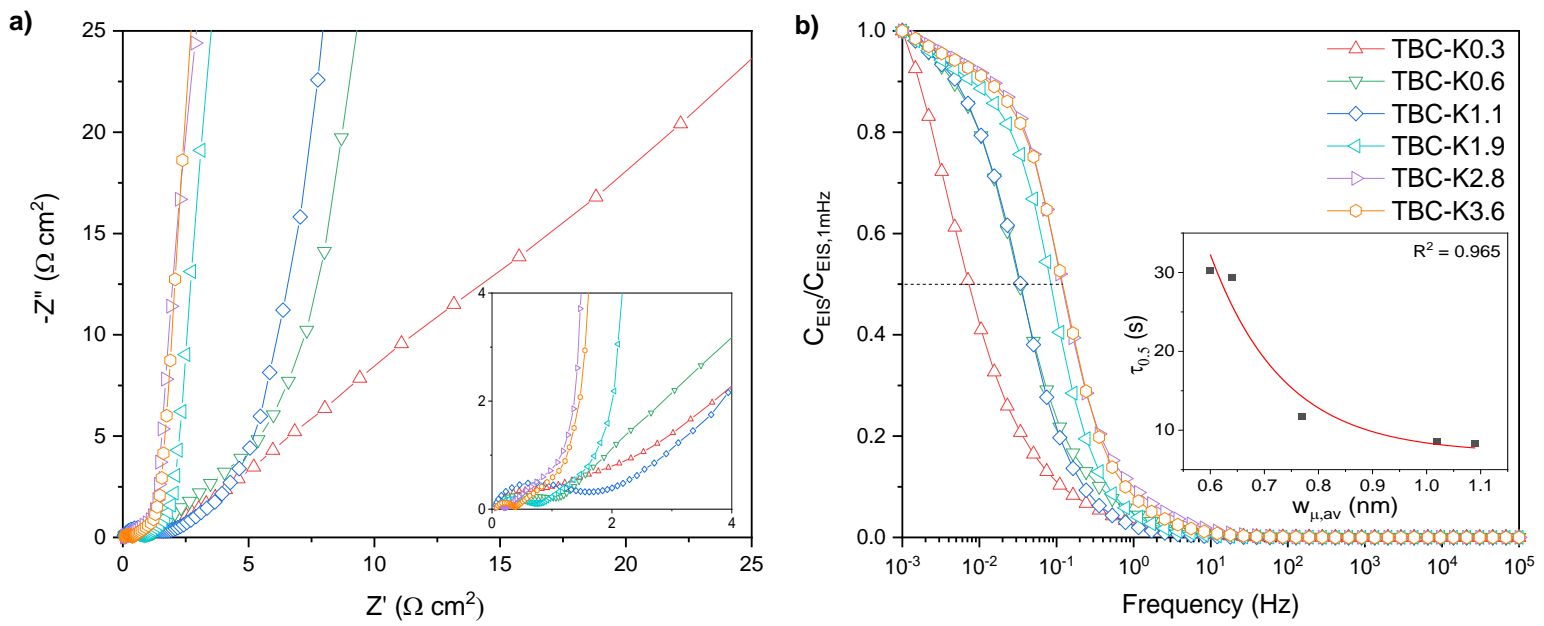

Figure 5. EIS results for symmetrical ECs based on biochar-derived ACs in aqueous $1 \mathrm{M}$ $\mathrm{H}_{2} \mathrm{SO}_{4}$ : (a) Nyquist plots of activated carbons (inset: zoom on the first parts of the curves); (b) normalized capacitance $\left(C_{E I S} / C_{E I S, 1 \mathrm{mHz}}\right)$ vs. frequency (inset: relaxation times vs. average micropore size). 
For a more in-depth interpretation of the electrochemical performance of activated biochars, galvanostatic charge/discharge cycling experiments were performed at different current densities. Examples of the results recorded for TBC-K2.8 are given in Figure S7, while Figure 6a shows a comparison of the galvanostatic charge-discharge curves at $2 \mathrm{~A} \mathrm{~g} \mathrm{~g}^{-1}$ for all materials. The ACs exhibited quasi-triangular voltage profiles indicating the preferential electrical double-layer storage mechanism $[68,84]$. The slight deviation from the linear and symmetrical voltage profiles is due to the occurrence of Faradaic reactions by pseudocapacitance. The materials prepared at high AR exhibited the lowest Ohmic drops $\left(I R_{d r o p}\right)$ in good agreement with the lowest internal resistances determined by EIS for these electrodes. A lower AR resulted in an increase of the $I R_{d r o p}$, indicating a higher electrical resistance. The capacitance retention at different current densities is displayed in Figure $\mathbf{6 b}$ for activated biochars with AR > 0.3. ECs based on TBC-K2.8 and TBC-K3.6 presented the largest $C_{\text {cell }}$ over the entire current density window with values of 50 and $60 \mathrm{~F} \mathrm{~g}^{-1}$ at $0.5 \mathrm{~A} \mathrm{~g}^{-1}$, respectively, which are close to those obtained by $\mathrm{CV}$ at $5 \mathrm{mV} \mathrm{s}^{-1}\left(\sim 60 \mathrm{~F} \mathrm{~g}^{-1}\right)$. Similar capacitances at low current densities have been reported for other biomass-derived carbon electrodes synthesized by pyrolysis and $\mathrm{KOH}$ activation (see Table 1), or for porous carbons obtained from tannin by different approaches [28,33-35]. Furthermore, TBC-K2.8 and TBCK3.6 exhibited the highest capacitance retentions $(64-70 \%)$ when the current density increased up to $10 \mathrm{~A} \mathrm{~g}^{-1}$. These results indicate easier diffusion of ions into the pores and faster electron transport. Although this rate capability is not exceptional in acidic media (see Table 1), most of the studies reported there used electrodes with a lower effective carbon loading (or the carbon loading has not been reported). A low carbon loading leads to an overestimation of the material capacitance by reducing the diffusion distance for the ions of the electrolyte, especially at high current densities $[44,46,47]$. In this work, the mass loading 
was comparable to the commercial standard, thus providing a more realistic insight into the electrochemical performance of activated biochars derived from pine tannin.
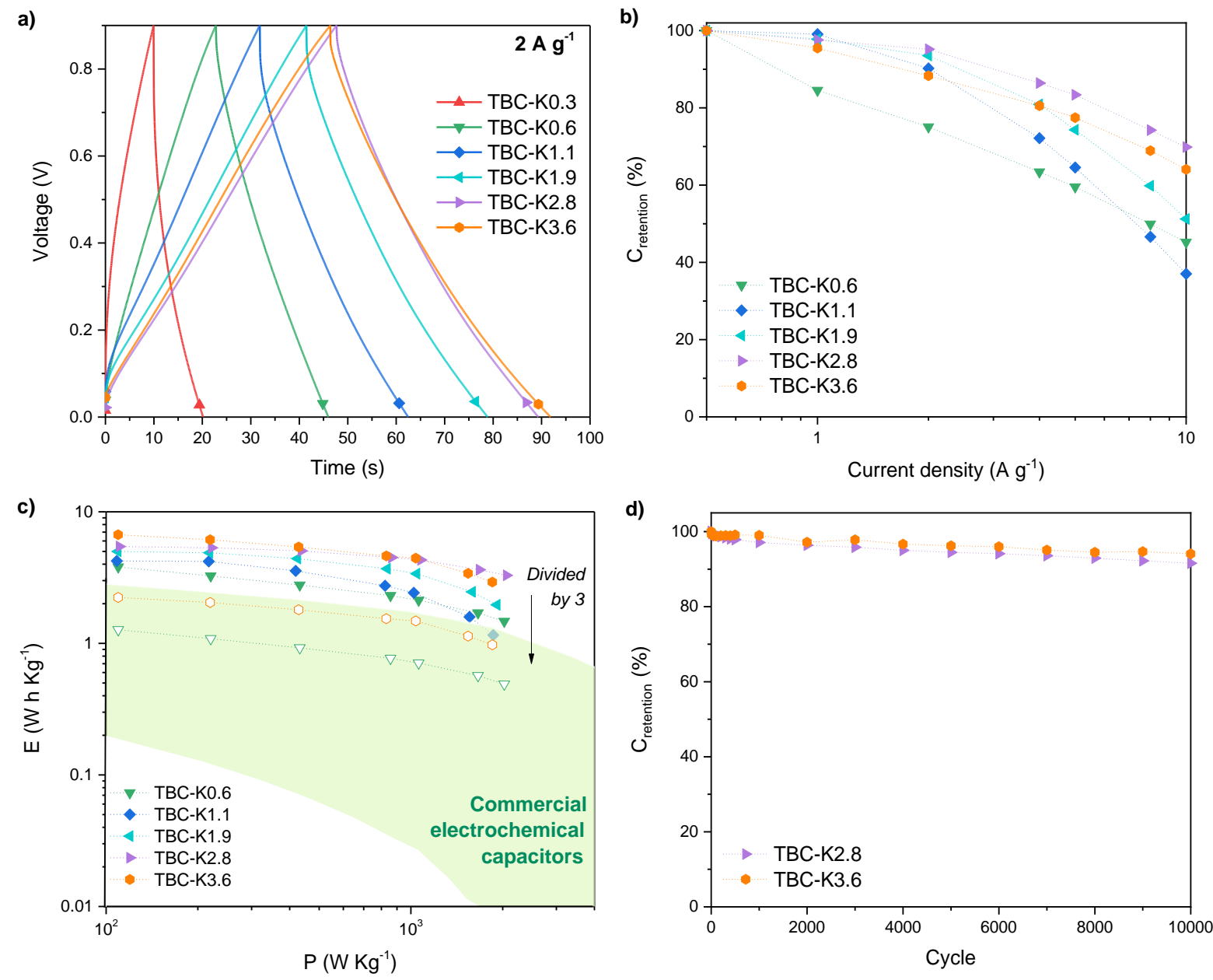

Figure 6. GCD results for symmetrical ECs based on biochar-derived ACs in the voltage range from 0 to $0.9 \mathrm{~V}$ in $1 \mathrm{M}$ aqueous $\mathrm{H}_{2} \mathrm{SO}_{4}$ : (a) galvanostatic charge-discharge profiles at 2 $\mathrm{A} \mathrm{g}^{-1}$; (b) specific capacitance retention as a function of the applied current density; (c) Ragone plots of symmetrical ECs based on activated biochars synthesized in this work (full symbols) and extrapolated power-energy curves of the packaged device obtained from dividing the specific energy values by a factor of 3 (empty symbols). For comparison purposes, commercial electrochemical capacitor technologies have been included as the green zone, (adapted from $[85,86]$ ); (d) stability at $5 \mathrm{~A} \mathrm{~g}^{-1}$ of ECs based on TBC-K2.8 and TBCK3.6. 
Table 1. Summary of biomass-derived carbon electrodes synthesized by pyrolysis and KOH activation for symmetrical ECs in aqueous acid media.

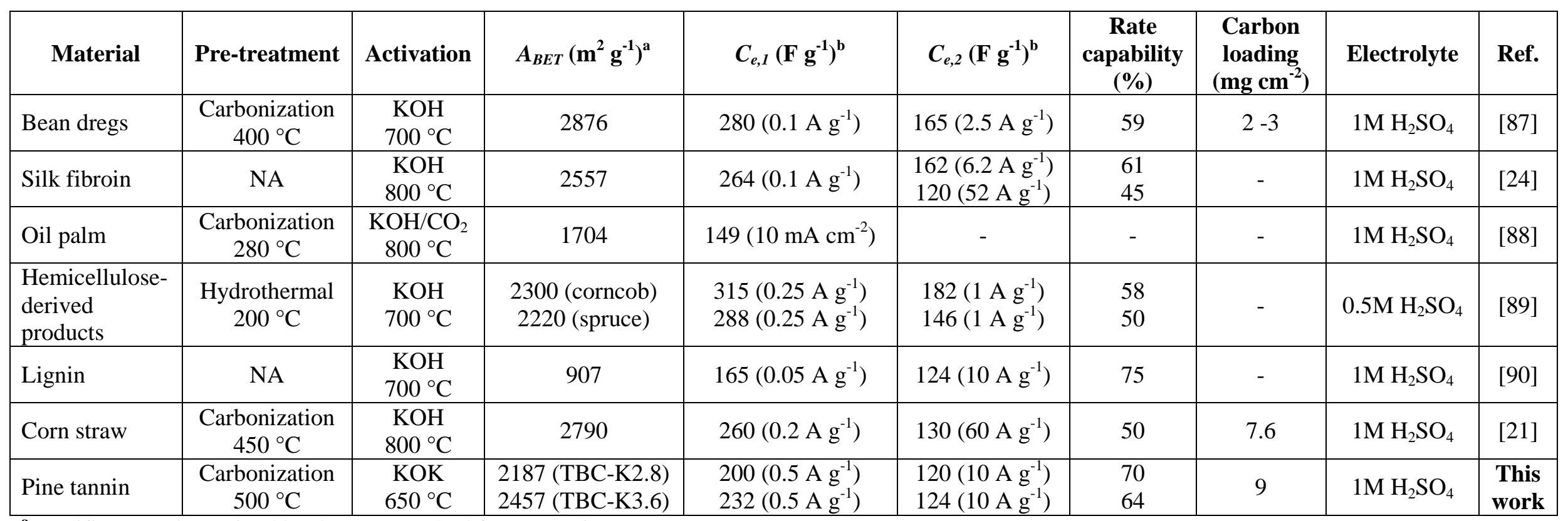

${ }^{\mathrm{a}}$ Specific areas determined by the BET method for comparison purposes.

${ }^{\mathbf{b}}$ Specific cell capacitances at the current density indicated in brackets. $C_{e, 1}$ and $C_{e, 2}$ are defined as the specific capacitances at the lowest and highest current density, respectively. 
The Ragone plot in Figure 6c compares the results of activated biochars with an AR above 0.3. The samples TBC-K2.8 and TBC-K3.6 exhibit the highest specific energies across the entire specific power range, confirming the improved storage performance of these materials. Their specific energies present a maximum of 5.4 and $6.7 \mathrm{~W} \mathrm{~h} \mathrm{~kg}{ }^{-1}$, respectively, at the specific power of $\sim 110 \mathrm{~W} \mathrm{~kg}^{-1}\left(0.5 \mathrm{~A} \mathrm{~g}^{-1}\right)$. These specific energies are higher than, or comparable to, those reported by other authors for ECs based on tannin-derived carbons in aqueous acidic media [27,28,33]. More importantly, at the power output of $1 \mathrm{~kW} \mathrm{~kg}^{-1}\left(5 \mathrm{~A} \mathrm{~g}^{-}\right.$ ${ }^{1}$ ), the stored energy for TBC-K2.8 and TBC-K3.6 is $\sim 4.4 \mathrm{~W} \mathrm{~h} \mathrm{~kg}^{-1}$, about twice as much as that obtained for TBC-K0.6 (2.3 $\left.\mathrm{W} \mathrm{h} \mathrm{kg}^{-1}\right)$, showing the importance of porosity development and pore widening during $\mathrm{KOH}$ activation.

From the performance of the materials, the specific energy of the commercial device can be extrapolated considering that the carbon weight is about $30 \%$ of the total mass of the packaged ECs $[45,46]$. This extrapolation is valid since similar commercial mass loadings (about $10 \mathrm{mg} \mathrm{cm}^{-2}$ ) have been used in this work. The extrapolated curves of the materials synthesized with the lowest and highest activating ratios (TBC-K0.6 and TBC-K3.6) are also plotted in Figure 6c (empty symbols). The ACs derived from tannin provide Ragone plots similar to those reported for commercial ECs $[85,86]$, demonstrating the applicability of these green and cost-effective materials as an alternative to ACs from petrochemical precursors. The stability of the TBC-K2.8- and TBC-K3.6-based ECs was evaluated by a long-term charge-discharge cycling at $5 \mathrm{~A} \mathrm{~g}^{-1}$ (Figure 6d). After 10,000 cycles, these systems retained 92 and $94 \%$ of their initial capacitance, respectively, evidencing the robustness of ECs based on $\mathrm{KOH}$-activated biochars derived from pyrolyzed tannin.

To better understand the practical use of tannin-derived activated biochars as EC electrodes, the leakage current and self-discharge of the most promising materials (TBC-K2.8 and TBCK3.6) were evaluated. The same experiments were carried out for a material synthesized at 
lower AR (TBC-K1.1) for the sake of comparison. Figure 7a shows the time-dependent leakage current at a cell voltage of $0.9 \mathrm{~V}$, while the spontaneous OCP decays after the devices were fully charged are given in Figure $\mathbf{7 b}$. The current sharply drops over time and then reaches a steady-state value after $\sim 500 \mathrm{~s}$ for the ECs containing tannin-derived activated biochars. The devices based on TBC-K1.1, TBC-K2.8 and TBC-K3.6 present a leakage current of around $0.15-0.17 \mathrm{~mA}\left(\sim 0.08-0.10 \mathrm{~A} \mathrm{~g} \mathrm{~g}^{-1}\right)$ at the end of $1 \mathrm{~h}$ of potential holding (see inset in Figure 7a). These values are in good agreement with those reported for other ACcontaining devices assembled in air and using aqueous $\mathrm{H}_{2} \mathrm{SO}_{4}$ electrolyte $(\sim 0.2-0.4 \mathrm{~mA})$ [51,52,91]. Additionally, the dissipation charge by leakage $\left(\sim 0.08-0.10 \mathrm{~A} \mathrm{~g}^{-1}\right)$ is 10 times lower than the charging current density $\left(1 \mathrm{~A} \mathrm{~g} \mathrm{~g}^{-1}\right)$, which shows the efficient charge of the ECs $[50]$.

As AR increases, a slightly lower steady-state current is noticed, which can be attributed to a lesser amount of unstable oxygen-containing species, which can undergo irreversible redox reactions or serve as reactive sites for carbon electrooxidation $[50,69,92]$. In line with these results, TBC-K2.8 and TBC-K3.6 had a lower oxygen content $\left(\mathrm{O}_{\mathrm{XPS}}=7.5\right.$ and 8.5 at.\%, Table S2) and a less pseudocapacitive contribution as evidenced by three-electrode electrochemical measurements.

Correspondingly, a more severe potential decay was observed for the cell based on TBC-K1.1 (Figure $7 \mathbf{b})$. Indeed, the time required to retain $50 \%$ of the initial voltage $\left(t_{0.45 \mathrm{~V}}\right)$ increases from ca. $6.9 \mathrm{~h}$ for TBC-K1.1 to $12.0 \mathrm{~h}$ and $13.3 \mathrm{~h}$ for TBC-K3.6 and TBC-K2.8, respectively. Similarly, the potential retention after $24 \mathrm{~h}$ of self-discharge follows the sequence: TBC-K1.1 $(29 \%)<$ TBC-K3.6 (36 \%) < TBC-K2.8 (38\%). The faster self-discharge of the former material is in good agreement with: i $)$ its higher content of oxygen-containing groups $\left(\mathrm{O}_{\mathrm{XPS}}=\right.$ 12.1 at.\%, Table S2), which results in a faster Faradaic reaction and; ii) its lower pore volume 
$\left(V_{\mathrm{NLDFT}}=0.49 \mathrm{~cm}^{3} \mathrm{~g}^{-1}\right.$, Table S1), which hinders charge redistribution by blocking access to the pores [49].
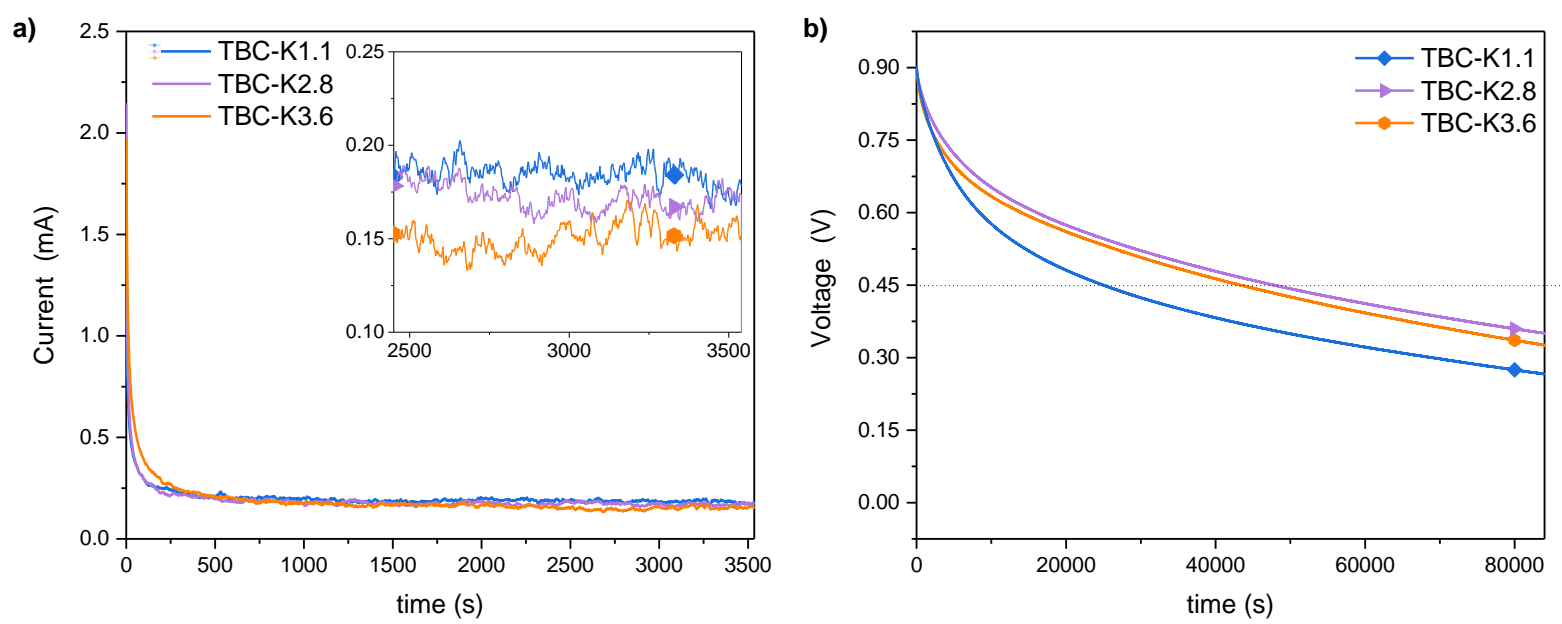

Figure 7. Leakage current and self-discharge results for symmetrical ECs based on biocharderived ACs in $1 \mathrm{M}$ aqueous $\mathrm{H}_{2} \mathrm{SO}_{4}$ : (a) time-dependent leakage current at $0.9 \mathrm{~V}$; (b) selfdischarge curves from $0.9 \mathrm{~V}$.

\section{Conclusions}

In this work, biochar obtained as a by-product of oil production by the fast pyrolysis of tannin from pine bark have been used as renewable source of activated carbons (ACs). Microporous ACs with outstanding surface areas (up to approx. $2200 \mathrm{~m}^{2} \mathrm{~g}^{-1}$ ) and high oxygen content (10 15 wt.\%) were obtained by direct activation of the biochar with $\mathrm{KOH}$ at $650{ }^{\circ} \mathrm{C}$. The assynthesized ACs were used as electrodes for electrochemical capacitors (ECs) in aqueous acid medium (1 $\left.\mathrm{M} \mathrm{H}_{2} \mathrm{SO}_{4}\right)$, achieving good performances when using commercial mass loadings (approx. $10 \mathrm{mg} \mathrm{cm}^{-2}$ ). Activation using a $\mathrm{KOH}$ to biochar mass ratio of 2.8 and 3.6 led to a good compromise between high surface areas and adequate pore size distributions, resulting in a high electrochemical specific capacitance (up to 220-230 $\mathrm{F} \mathrm{g}^{-1}$ ) with a capacitance retention of $64-70 \%$ when increasing the current density from 0.5 to $10 \mathrm{~A} \mathrm{~g}^{-1}$. In addition, the materials presented long-term stability retaining 92 and $94 \%$ of the initial energy storage after 
10,000 cycles. Therefore, the upgrading of biochars derived from the pyrolysis of pine tannin as ECs electrodes is a viable alternative to their combustion while improving the economic balance of pyrolysis oil production.

\section{Acknowledgments}

This study was partly supported by the French PIA project "Lorraine Université d'Excellence", reference ANR-15-IDEX-04-LUE and the TALiSMAN project funded by ERDF. O. Pinto thanks ANID - Subdirección de Capital Humano/Doctorado, \# 2019/21190633. P.S. Poon and C. Segura thank ANID-PIA/APOYO CCTE AFB170007 project. J. Matos acknowledges the funds from the Chilean projects ANID-FONDEF ID19I10003; ANID-FONDECYT 1190591; and Millennium Science Initiative ProgramNCN17-040. J. Matos also thanks the Technological Development UNIT (UDT) from the University of Concepción (Chile), for supplying the tannin-derived chars. The authors finally thank Philippe Gadonneix for his technical assistance in laboratory measurements at Université de Lorraine.

\section{Conflict of interest}

The authors declare that they have no known competing financial interests or personal relationships that might appear to influence the work described in this paper.

\section{Authors' contributions}

S. Perez-Rodriguez performed investigation, conceptualization, formal analysis and writing original draft, writing - review and editing; O. Pinto and C. Segura performed investigation; P.S. Poon and M. T. Izquierdo performed investigation and formal analysis; A. Celzard performed Raman spectroscopy, formal analysis and writing - review \& editing; J. Matos and 
V. Fierro performed conceptualization, supervision, funding acquisition and writing - review and editing.

\section{References}

[1] C. Zhong, Y. Deng, W. Hu, J. Qiao, L. Zhang, J. Zhang, A review of electrolyte materials and compositions for electrochemical supercapacitors, Chem. Soc. Rev. 44 (2015) 7484-7539. https://doi.org/10.1039/C5CS00303B.

[2] J. Castro-Gutiérrez, A. Celzard, V. Fierro, Energy Storage in Supercapacitors: Focus on TanninDerived Carbon Electrodes, Front. Mater. 7 (2020). https://doi.org/10.3389/fmats.2020.00217.

[3] P. Sharma, T.S. Bhatti, A review on electrochemical double-layer capacitors, Energy Convers. Manag. 51 (2010) 2901-2912. https://doi.org/10.1016/j.enconman.2010.06.031.

[4] L. Qie, W. Chen, H. Xu, X. Xiong, Y. Jiang, F. Zou, X. Hu, Y. Xin, Z. Zhang, Y. Huang, Synthesis of functionalized 3D hierarchical porous carbon for high-performance supercapacitors, Energy Environ. Sci. 6 (2013) 2497-2504. https://doi.org/10.1039/C3EE41638K.

[5] J. Zhang, X.S. Zhao, On the Configuration of Supercapacitors for Maximizing Electrochemical Performance, ChemSusChem. 5 (2012) 818-841. https://doi.org/10.1002/cssc.201100571.

[6] Y. Wang, Q. Qu, S. Gao, G. Tang, K. Liu, S. He, C. Huang, Biomass derived carbon as binder-free electrode materials for supercapacitors, Carbon. 155 (2019) 706-726. https://doi.org/10.1016/j.carbon.2019.09.018.

[7] H. Lu, X.S. Zhao, Biomass-derived carbon electrode materials for supercapacitors, Sustain. Energy Fuels. 1 (2017) 1265-1281. https://doi.org/10.1039/C7SE00099E.

[8] L. Wei, M. Sevilla, A.B. Fuertes, R. Mokaya, G. Yushin, Hydrothermal Carbonization of Abundant Renewable Natural Organic Chemicals for High-Performance Supercapacitor Electrodes, Adv. Energy Mater. 1 (2011) 356-361. https://doi.org/10.1002/aenm.201100019.

[9] Z. Bi, Q. Kong, Y. Cao, G. Sun, F. Su, X. Wei, X. Li, A. Ahmad, L. Xie, C.-M. Chen, Biomass-derived porous carbon materials with different dimensions for supercapacitor electrodes: a review, J. Mater. Chem. A. 7 (2019) 16028-16045. https://doi.org/10.1039/C9TA04436A.

[10] C.-H. Wang, W.-C. Wen, H.-C. Hsu, B.-Y. Yao, High-capacitance KOH-activated nitrogencontaining porous carbon material from waste coffee grounds in supercapacitor, Adv. Powder Technol. 27 (2016) 1387-1395. https://doi.org/10.1016/j.apt.2016.04.033.

[11] X. Liu, S. Zhang, X. Wen, X. Chen, Y. Wen, X. Shi, E. Mijowska, High yield conversion of biowaste coffee grounds into hierarchical porous carbon for superior capacitive energy storage, Sci. Rep. 10 (2020) 3518. https://doi.org/10.1038/s41598-020-60625-y.

[12] S. Sarkar, A. Arya, U.K. Gaur, A. Gaur, Investigations on porous carbon derived from sugarcane bagasse as an electrode material for supercapacitors, Biomass Bioenergy. 142 (2020) 105730. https://doi.org/10.1016/j.biombioe.2020.105730.

[13] W. Qian, F. Sun, Y. Xu, L. Qiu, C. Liu, S. Wang, F. Yan, Human hair-derived carbon flakes for electrochemical supercapacitors, Energy Environ. Sci. 7 (2013) 379-386. https://doi.org/10.1039/C3EE43111H.

[14] M. Vijayakumar, A. Bharathi Sankar, D. Sri Rohita, T.N. Rao, M. Karthik, Conversion of Biomass Waste into High Performance Supercapacitor Electrodes for Real-Time Supercapacitor Applications, ACS Sustain. Chem. Eng. 7 (2019) 17175-17185.

https://doi.org/10.1021/acssuschemeng.9b03568.

[15] M. Sevilla, R. Mokaya, Energy storage applications of activated carbons: supercapacitors and hydrogen storage, Energy Environ. Sci. 7 (2014) 1250-1280. https://doi.org/10.1039/C3EE43525C.

[16] J. Wang, S. Kaskel, KOH activation of carbon-based materials for energy storage, J. Mater. Chem. 22 (2012) 23710-23725. https://doi.org/10.1039/C2JM34066F. 
[17] G. Lin, R. Ma, Y. Zhou, Q. Liu, X. Dong, J. Wang, KOH activation of biomass-derived nitrogendoped carbons for supercapacitor and electrocatalytic oxygen reduction, Electrochimica Acta. 261 (2018) 49-57. https://doi.org/10.1016/j.electacta.2017.12.107.

[18] S. Ghosh, R. Santhosh, S. Jeniffer, V. Raghavan, G. Jacob, K. Nanaji, P. Kollu, S.K. Jeong, A.N. Grace, Natural biomass derived hard carbon and activated carbons as electrochemical supercapacitor electrodes, Sci. Rep. 9 (2019) 16315. https://doi.org/10.1038/s41598-01952006-x.

[19] N. Guo, M. Li, X. Sun, F. Wang, R. Yang, Enzymatic hydrolysis lignin derived hierarchical porous carbon for supercapacitors in ionic liquids with high power and energy densities, Green Chem. 19 (2017) 2595-2602. https://doi.org/10.1039/C7GC00506G.

[20] Q. Zhang, K. Han, S. Li, M. Li, J. Li, K. Ren, Synthesis of garlic skin-derived 3D hierarchical porous carbon for high-performance supercapacitors, Nanoscale. 10 (2018) 2427-2437. https://doi.org/10.1039/C7NR07158B.

[21] Z. Qiu, Y. Wang, X. Bi, T. Zhou, J. Zhou, J. Zhao, Z. Miao, W. Yi, P. Fu, S. Zhuo, Biochar-based carbons with hierarchical micro-meso-macro porosity for high rate and long cycle life supercapacitors, J. Power Sources. 376 (2018) 82-90. https://doi.org/10.1016/j.jpowsour.2017.11.077.

[22] J. Pang, W. Zhang, J. Zhang, G. Cao, M. Han, Y. Yang, Facile and sustainable synthesis of sodium lignosulfonate derived hierarchical porous carbons for supercapacitors with high volumetric energy densities, Green Chem. 19 (2017) 3916-3926. https://doi.org/10.1039/C7GC01434A.

[23] B. Wang, Y. Wang, Y. Peng, X. Wang, J. Wang, J. Zhao, 3-dimensional interconnected framework of $\mathrm{N}$-doped porous carbon based on sugarcane bagasse for application in supercapacitors and lithium ion batteries, J. Power Sources. 390 (2018) 186-196. https://doi.org/10.1016/j.jpowsour.2018.04.056.

[24] Y.S. Yun, S.Y. Cho, J. Shim, B.H. Kim, S.-J. Chang, S.J. Baek, Y.S. Huh, Y. Tak, Y.W. Park, S. Park, H.J. Jin, Microporous Carbon Nanoplates from Regenerated Silk Proteins for Supercapacitors, Adv. Mater. 25 (2013) 1993-1998. https://doi.org/10.1002/adma.201204692.

[25] Y. Shirmohammadli, D. Efhamisisi, A. Pizzi, Tannins as a sustainable raw material for green chemistry: A review, Ind. Crops Prod. 126 (2018) 316-332. https://doi.org/10.1016/j.indcrop.2018.10.034.

[26] A. Arenillas, J.A. Menéndez, G. Reichenauer, A. Celzard, V. Fierro, F.J. Maldonado Hodar, E. Bailón-Garcia, N. Job, Organic and Carbon Gels Derived from Biosourced Polyphenols, in: A. Arenillas, J.A. Menéndez, G. Reichenauer, A. Celzard, V. Fierro, F.J. Maldonado Hodar, E. BailónGarcia, N. Job (Eds.), Org. Carbon Gels Lab. Synth. Appl., Springer International Publishing, Cham, 2019: pp. 27-85. https://doi.org/10.1007/978-3-030-13897-4_2.

[27] J. Castro-Gutiérrez, A. Sanchez-Sanchez, J. Ghanbaja, N. Díez, M. Sevilla, A. Celzard, V. Fierro, Synthesis of perfectly ordered mesoporous carbons by water-assisted mechanochemical selfassembly of tannin, Green Chem. 20 (2018) 5123-5132. https://doi.org/10.1039/C8GC02295J.

[28] A. Sanchez-Sanchez, M.T. Izquierdo, G. Medjahdi, J. Ghanbaja, A. Celzard, V. Fierro, Ordered mesoporous carbons obtained by soft-templating of tannin in mild conditions, Microporous Mesoporous Mater. 270 (2018) 127-139. https://doi.org/10.1016/j.micromeso.2018.05.017.

[29] F.L. Braghiroli, G. Amaral-Labat, A.F.N. Boss, C. Lacoste, A. Pizzi, Tannin Gels and Their Carbon Derivatives: A Review, Biomolecules. 9 (2019). https://doi.org/10.3390/biom9100587.

[30] G. Amaral-Labat, L.I. Grishechko, V. Fierro, B.N. Kuznetsov, A. Pizzi, A. Celzard, Tannin-based xerogels with distinctive porous structures, Biomass Bioenergy. 56 (2013) 437-445. https://doi.org/10.1016/j.biombioe.2013.06.001.

[31] C. Delgado-Sánchez, F. Santiago-Medina, V. Fierro, A. Pizzi, A. Celzard, Optimisation of "green" tannin-furanic foams for thermal insulation by experimental design, Mater. Des. 139 (2018) 715. https://doi.org/10.1016/j.matdes.2017.10.064.

[32] L.I. Grishechko, G. Amaral-Labat, V. Fierro, A. Szczurek, B.N. Kuznetsov, A. Celzard, Biosourced, highly porous, carbon xerogel microspheres, RSC Adv. 6 (2016) 65698-65708. https://doi.org/10.1039/C6RA09462G. 
[33] J. Castro-Gutiérrez, N. Díez, M. Sevilla, M.T. Izquierdo, J. Ghanbaja, A. Celzard, V. Fierro, HighRate Capability of Supercapacitors Based on Tannin-Derived Ordered Mesoporous Carbons, ACS Sustain. Chem. Eng. 7 (2019) 17627-17635. https://doi.org/10.1021/acssuschemeng.9b03407.

[34] A. Sanchez-Sanchez, M.T. Izquierdo, S. Mathieu, J. González-Álvarez, A. Celzard, V. Fierro, Outstanding electrochemical performance of highly $\mathrm{N}$ - and O-doped carbons derived from pine tannin, Green Chem. 19 (2017) 2653-2665. https://doi.org/10.1039/C7GC00491E.

[35] A. Sanchez-Sanchez, M.T. Izquierdo, J. Ghanbaja, G. Medjahdi, S. Mathieu, A. Celzard, V. Fierro, Excellent electrochemical performances of nanocast ordered mesoporous carbons based on tannin-related polyphenols as supercapacitor electrodes, J. Power Sources. 344 (2017) 15-24. https://doi.org/10.1016/j.jpowsour.2017.01.099.

[36] F.L. Braghiroli, V. Fierro, A. Szczurek, N. Stein, J. Parmentier, A. Celzard, Hydrothermally treated aminated tannin as precursor of $\mathrm{N}$-doped carbon gels for supercapacitors, Carbon. 90 (2015) 63-74. https://doi.org/10.1016/j.carbon.2015.03.038.

[37] F.L. Braghiroli, V. Fierro, J. Parmentier, A. Pasc, A. Celzard, Easy and eco-friendly synthesis of ordered mesoporous carbons by self-assembly of tannin with a block copolymer, Green Chem. 18 (2016) 3265-3271. https://doi.org/10.1039/C5GC02788H.

[38] A. Gysling, V. Álvarez, D. Soto, E. Pardo, R. Toledo, P. Poblete, P. González, J. Bañados, Chilean Statistical Yearbook of Forestry, Ministry of Agriculture., Bulletin of Forestry 154 (2016) 70-72. (n.d.).

[39] H. Kofujita, K. Ettyu, M. Ota, Characterization of the major components in bark from five Japanese tree species for chemical utilization, Wood Sci. Technol. 33 (1999) 223-228. https://doi.org/10.1007/s002260050111.

[40] O. Pinto, R. Romero, M. Carrier, J. Appelt, C. Segura, Fast pyrolysis of tannins from pine bark as a renewable source of catechols, J. Anal. Appl. Pyrolysis. 136 (2018) 69-76. https://doi.org/10.1016/j.jaap.2018.10.022.

[41] A. Moore, S. Park, C. Segura, M. Carrier, Fast pyrolysis of lignin-coated radiata pine, J. Anal. Appl. Pyrolysis. 115 (2015) 203-213. https://doi.org/10.1016/j.jaap.2015.07.017.

[42] J. Jagiello, C. Ania, J.B. Parra, C. Cook, Dual gas analysis of microporous carbons using 2D-NLDFT heterogeneous surface model and combined adsorption data of N2 and CO2, Carbon. 91 (2015) 330-337. https://doi.org/10.1016/j.carbon.2015.05.004.

[43] G. Rasines, C. Macías, M. Haro, J. Jagiello, C.O. Ania, Effects of $\mathrm{CO} 2$ activation of carbon aerogels leading to ultrahigh micro-meso porosity, Microporous Mesoporous Mater. 209 (2015) 18-22. https://doi.org/10.1016/j.micromeso.2015.01.011.

[44] L. Chang, Y.H. Hu, Breakthroughs in Designing Commercial-Level Mass-Loading Graphene Electrodes for Electrochemical Double-Layer Capacitors, Matter. 1 (2019) 596-620. https://doi.org/10.1016/j.matt.2019.06.016.

[45] M. Sevilla, N. Diez, G.A. Ferrero, A.B. Fuertes, Sustainable supercapacitor electrodes produced by the activation of biomass with sodium thiosulfate, Energy Storage Mater. 18 (2019) 356365. https://doi.org/10.1016/j.ensm.2019.01.023.

[46] Y. Gogotsi, P. Simon, True Performance Metrics in Electrochemical Energy Storage, Science. 334 (2011) 917-918. https://doi.org/10.1126/science.1213003.

[47] M.D. Stoller, R.S. Ruoff, Best practice methods for determining an electrode material's performance for ultracapacitors, Energy Environ. Sci. 3 (2010) 1294-1301. https://doi.org/10.1039/COEE00074D.

[48] A.B. Fuertes, G.A. Ferrero, M. Sevilla, Commentary: Methods of calculating the volumetric performance of a supercapacitor, Energy Storage Mater. 4 (2016) 154-155. https://doi.org/10.1016/j.ensm.2016.05.002.

[49] B. Gu, H. Su, X. Chu, Q. Wang, H. Huang, J. He, T. Wu, W. Deng, H. Zhang, W. Yang, Rationally assembled porous carbon superstructures for advanced supercapacitors, Chem. Eng. J. 361 (2019) 1296-1303. https://doi.org/10.1016/j.cej.2019.01.007.

[50] M. Haque, Q. Li, A.D. Smith, V. Kuzmenko, P. Rudquist, P. Lundgren, P. Enoksson, Self-discharge and leakage current mitigation of neutral aqueous-based supercapacitor by means of liquid 
crystal additive, J. Power Sources. 453 (2020) 227897.

https://doi.org/10.1016/j.jpowsour.2020.227897.

[51] C. Wu, X. Wang, B. Ju, Y. Bai, L. Jiang, H. Wu, Q. Zhao, J. Gao, X. Wang, L. Yi, Supercapacitive behaviors of the nitrogen-enriched activated mesocarbon microbead in aqueous electrolytes, $\mathrm{J}$. Solid State Electrochem. 17 (2013) 1693-1700. https://doi.org/10.1007/s10008-013-2038-y.

[52] X. Zhang, X. Wang, L. Jiang, H. Wu, C. Wu, J. Su, Effect of aqueous electrolytes on the electrochemical behaviors of supercapacitors based on hierarchically porous carbons, J. Power Sources. 216 (2012) 290-296. https://doi.org/10.1016/j.jpowsour.2012.05.090.

[53] G. Xu, J. Han, B. Ding, P. Nie, J. Pan, H. Dou, H. Li, X. Zhang, Biomass-derived porous carbon materials with sulfur and nitrogen dual-doping for energy storage, Green Chem. 17 (2015) 1668-1674. https://doi.org/10.1039/C4GC02185A.

[54] J.V. Nabais, P. Carrott, M.M.L. Ribeiro Carrott, V. Luz, A.L. Ortiz, Influence of preparation conditions in the textural and chemical properties of activated carbons from a novel biomass precursor: The coffee endocarp, Bioresour. Technol. 99 (2008) 7224-7231. https://doi.org/10.1016/j.biortech.2007.12.068.

[55] L. Jiang, J. Yan, L. Hao, R. Xue, G. Sun, B. Yi, High rate performance activated carbons prepared from ginkgo shells for electrochemical supercapacitors, Carbon. 56 (2013) 146-154. https://doi.org/10.1016/j.carbon.2012.12.085.

[56] J. Singh, H. Bhunia, S. Basu, Adsorption of $\mathrm{CO} 2$ on KOH activated carbon adsorbents: Effect of different mass ratios, J. Environ. Manage. 250 (2019) 109457. https://doi.org/10.1016/j.jenvman.2019.109457.

[57] J. Matos, M. Labady, A. Albornoz, J. Laine, J.L. Brito, Catalytic effect of KOH on textural changes of carbon macro-networks by physical activation, J. Mol. Catal. Chem. 228 (2005) 189-194. https://doi.org/10.1016/j.molcata.2004.09.039.

[58] J. Matos, V. Fierro, R. Montaña, E. Rivero, A.M. de Yuso, W. Zhao, A. Celzard, High surface area microporous carbons as photoreactors for the catalytic photodegradation of methylene blue under UV-vis irradiation, Appl. Catal. Gen. 517 (2016) 1-11. https://doi.org/10.1016/j.apcata.2016.02.031.

[59] M. Thommes, K. Kaneko, A.V. Neimark, J.P. Olivier, F. Rodriguez-Reinoso, J. Rouquerol, K.S.W. Sing, Physisorption of gases, with special reference to the evaluation of surface area and pore size distribution (IUPAC Technical Report), Pure Appl. Chem. 87 (2015) 1051-1069. https://doi.org/10.1515/pac-2014-1117.

[60] J. Huang, B.G. Sumpter, V. Meunier, A Universal Model for Nanoporous Carbon Supercapacitors Applicable to Diverse Pore Regimes, Carbon Materials, and Electrolytes, Chem. - Eur. J. 14 (2008) 6614-6626. https://doi.org/10.1002/chem.200800639.

[61] F. Xu, R. Cai, Q. Zeng, C. Zou, D. Wu, F. Li, X. Lu, Y. Liang, R. Fu, Fast ion transport and high capacitance of polystyrene-based hierarchical porous carbon electrode material for supercapacitors, J. Mater. Chem. 21 (2011) 1970-1976. https://doi.org/10.1039/C0JM02044C.

[62] K. Xia, Q. Gao, J. Jiang, J. Hu, Hierarchical porous carbons with controlled micropores and mesopores for supercapacitor electrode materials, Carbon. 46 (2008) 1718-1726. https://doi.org/10.1016/j.carbon.2008.07.018.

[63] T.A. Centeno, F. Stoeckli, The assessment of surface areas in porous carbons by two modelindependent techniques, the DR equation and DFT, Carbon. 48 (2010) 2478-2486. https://doi.org/10.1016/j.carbon.2010.03.020.

[64] G. Lota, T.A. Centeno, E. Frackowiak, F. Stoeckli, Improvement of the structural and chemical properties of a commercial activated carbon for its application in electrochemical capacitors, Electrochimica Acta. 53 (2008) 2210-2216. https://doi.org/10.1016/j.electacta.2007.09.028.

[65] S. Brunauer, P.H. Emmett, E. Teller, Adsorption of Gases in Multimolecular Layers, J. Am. Chem. Soc. 60 (1938) 309-319. https://doi.org/10.1021/ja01269a023.

[66] J. Landers, G.Yu. Gor, A.V. Neimark, Density functional theory methods for characterization of porous materials, Colloids Surf. Physicochem. Eng. Asp. 437 (2013) 3-32. https://doi.org/10.1016/j.colsurfa.2013.01.007. 
[67] A. Sanchez-Sanchez, A.M. de Yuso, F.L. Braghiroli, M.T. Izquierdo, E.D. Alvarez, E. Pérez-Cappe, Y. Mosqueda, V. Fierro, A. Celzard, Sugarcane molasses as a pseudocapacitive material for supercapacitors, RSC Adv. 6 (2016) 88826-88836. https://doi.org/10.1039/C6RA16314A.

[68] M. Sevilla, A.B. Fuertes, Direct Synthesis of Highly Porous Interconnected Carbon Nanosheets and Their Application as High-Performance Supercapacitors, ACS Nano. 8 (2014) 5069-5078. https://doi.org/10.1021/nn501124h.

[69] C.-T. Hsieh, H. Teng, Influence of oxygen treatment on electric double-layer capacitance of activated carbon fabrics, Carbon. 40 (2002) 667-674. https://doi.org/10.1016/S00086223(01)00182-8.

[70] D. Qu, Studies of the activated carbons used in double-layer supercapacitors, J. Power Sources. 109 (2002) 403-411. https://doi.org/10.1016/S0378-7753(02)00108-8.

[71] Y.-R. Nian, H. Teng, Influence of surface oxides on the impedance behavior of carbon-based electrochemical capacitors, J. Electroanal. Chem. 540 (2003) 119-127. https://doi.org/10.1016/S0022-0728(02)01299-8.

[72] M. Sevilla, S. Álvarez, T.A. Centeno, A.B. Fuertes, F. Stoeckli, Performance of templated mesoporous carbons in supercapacitors, Electrochimica Acta. 52 (2007) 3207-3215. https://doi.org/10.1016/j.electacta.2006.09.063.

[73] M.-H. Kim, K.-B. Kim, S.-M. Park, K.C. Roh, Hierarchically structured activated carbon for ultracapacitors, Sci. Rep. 6 (2016) 21182. https://doi.org/10.1038/srep21182.

[74] S. Pérez-Rodríguez, G. García, M.J. Lázaro, E. Pastor, DEMS strategy for the determination of the difference in surface acidity of carbon materials, Electrochem. Commun. 90 (2018) 87-90. https://doi.org/10.1016/j.elecom.2018.04.014.

[75] T.A. Centeno, F. Stoeckli, Surface-related capacitance of microporous carbons in aqueous and organic electrolytes, Electrochimica Acta. 56 (2011) 7334-7339. https://doi.org/10.1016/j.electacta.2011.06.040.

[76] B.-A. Mei, O. Munteshari, J. Lau, B. Dunn, L. Pilon, Physical Interpretations of Nyquist Plots for EDLC Electrodes and Devices, J. Phys. Chem. C. 122 (2018) 194-206. https://doi.org/10.1021/acs.jpcc.7b10582.

[77] T.S. Mathis, N. Kurra, X. Wang, D. Pinto, P. Simon, Y. Gogotsi, Energy Storage Data Reporting in Perspective-Guidelines for Interpreting the Performance of Electrochemical Energy Storage Systems, Adv. Energy Mater. 9 (2019) 1902007. https://doi.org/10.1002/aenm.201902007.

[78] M.I. Nathan, J.E. Smith, K.N. Tu, Raman spectra of glassy carbon, J. Appl. Phys. 45 (1974) 23702370. https://doi.org/10.1063/1.1663599.

[79] R.O. Dillon, J.A. Woollam, V. Katkanant, Use of Raman scattering to investigate disorder and crystallite formation in as-deposited and annealed carbon films, Phys. Rev. B. 29 (1984) 34823489. https://doi.org/10.1103/PhysRevB.29.3482.

[80] A.C. Ferrari, J. Robertson, Interpretation of Raman spectra of disordered and amorphous carbon, Phys. Rev. B. 61 (2000) 14095-14107. https://doi.org/10.1103/PhysRevB.61.14095.

[81] A. Szczurek, A. Ortona, L. Ferrari, E. Rezaei, G. Medjahdi, V. Fierro, D. Bychanok, P. Kuzhir, A. Celzard, Carbon periodic cellular architectures, Carbon. 88 (2015) 70-85. https://doi.org/10.1016/j.carbon.2015.02.069.

[82] A. Celzard, V. Fierro, "Green", innovative, versatile and efficient carbon materials from polyphenolic plant extracts, Carbon. (2020). https://doi.org/10.1016/j.carbon.2020.05.053.

[83] M.F. El-Kady, V. Strong, S. Dubin, R.B. Kaner, Laser Scribing of High-Performance and Flexible Graphene-Based Electrochemical Capacitors, Science. 335 (2012) 1326-1330. https://doi.org/10.1126/science.1216744.

[84] D. Wang, Z. Geng, B. Li, C. Zhang, High performance electrode materials for electric doublelayer capacitors based on biomass-derived activated carbons, Electrochimica Acta. 173 (2015) 377-384. https://doi.org/10.1016/j.electacta.2015.05.080.

[85] P. Simon, Y. Gogotsi, Materials for electrochemical capacitors, Nat. Mater. 7 (2008) 845-854. https://doi.org/10.1038/nmat2297. 
[86] M. Zschornak, F. Meutzner, J. Lück, A. Latz, T. Leisegang, J. Hanzig, M. Nentwich, J. Zosel, P.B. Balbuena, Fundamental principles of battery design, Phys. Sci. Rev. 3 (2018). https://doi.org/10.1515/psr-2017-0111.

[87] C. Ruan, K. Ai, L. Lu, Biomass-derived carbon materials for high-performance supercapacitor electrodes, RSC Adv. 4 (2014) 30887-30895. https://doi.org/10.1039/C4RA04470C.

[88] R. Farma, M. Deraman, A. Awitdrus, I.A. Talib, E. Taer, N.H. Basri, J.G. Manjunatha, M.M. Ishak, B.N.M. Dollah, S.A. Hashmi, Preparation of highly porous binderless activated carbon electrodes from fibres of oil palm empty fruit bunches for application in supercapacitors, Bioresour. Technol. 132 (2013) 254-261. https://doi.org/10.1016/j.biortech.2013.01.044.

[89] C. Falco, J.M. Sieben, N. Brun, M. Sevilla, T. van der Mauelen, E. Morallón, D. Cazorla-Amorós, M.-M. Titirici, Hydrothermal Carbons from Hemicellulose-Derived Aqueous Hydrolysis Products as Electrode Materials for Supercapacitors, ChemSusChem. 6 (2013) 374-382. https://doi.org/10.1002/cssc.201200817.

[90] W. Zhang, H. Lin, Z. Lin, J. Yin, H. Lu, D. Liu, M. Zhao, 3 D Hierarchical Porous Carbon for Supercapacitors Prepared from Lignin through a Facile Template-Free Method, ChemSusChem. 8 (2015) 2114-2122. https://doi.org/10.1002/cssc.201403486.

[91] H. Wada, K. Yoshikawa, S. Nohara, N. Furukawa, H. Inoue, N. Sugoh, H. Iwasaki, C. Iwakura, Electrochemical characteristics of new electric double layer capacitor with acidic polymer hydrogel electrolyte, J. Power Sources. 159 (2006) 1464-1467. https://doi.org/10.1016/j.jpowsour.2005.11.073.

[92] W. Ma, L. Xie, L. Dai, G. Sun, J. Chen, F. Su, Y. Cao, H. Lei, Q. Kong, C.-M. Chen, Influence of phosphorus doping on surface chemistry and capacitive behaviors of porous carbon electrode, Electrochimica Acta. 266 (2018) 420-430. https://doi.org/10.1016/j.electacta.2018.02.031. 


\section{Figure captions}

Figure 1. (a) $\mathrm{N}_{2}$ adsorption-desorption isotherms at $-196^{\circ} \mathrm{C}$; (b) $\mathrm{CO}_{2}$ isotherms at $0{ }^{\circ} \mathrm{C}$; (c) specific areas determined by BET and NLDFT methods as a function of the activating ratio (AR); (d) variation of the pore volumes (total, micropores, ultramicropores and mesopores) obtained by the NLDFT method when combining both $\mathrm{N}_{2}$ and $\mathrm{CO}_{2}$ adsorption data; (e) PSD determined by applying the NLDFT method on both $\mathrm{N}_{2}$ and $\mathrm{CO}_{2}$ isotherms; (f) cumulative pore volume as a function of the average pore width of biochar-derived ACs. Dotted curves are just guides for the eye.

Figure 2. (a) Bulk and surface oxygen content (wt.\%) obtained by elemental analysis (EA) and XPS, respectively; (b) atomic oxygen obtained by EA and XPS and normalized with respect to specific area determined by BET and NLDFT methods as a function of the activating ratio (AR); (c) relative atomic $\mathrm{C} 1 \mathrm{~s}$ and (d) O1s contributions from XPS of biocharderived ACs at different ARs. Dotted curves are just guides for the eye.

Figure 3. (a) TEM image of TBC-K1.1 and corresponding chemical mapping of C and $\mathrm{O}$; and TEM images of (b) TBC, (c) TBC-K1.1 and (d) TBC-K3.6.

Figure 4. Results from $\mathrm{CV}$ of biochar-derived $\mathrm{ACs}$ in aqueous $1 \mathrm{M} \mathrm{H}_{2} \mathrm{SO}_{4}$ : (a) curves of cell capacitance vs. voltage at $5 \mathrm{mV} \mathrm{s}^{-1}$ obtained in symmetrical ECs; (b) cell capacitance obtained in symmetrical ECs as a function of activating ratio (AR) and as a function of specific surface area determined by 2 D-NLDFT-HS method $\left(S_{N L D F T}\right.$, see inset) at $5 \mathrm{mV} \mathrm{s}^{-1}$; (c) electrode capacitance obtained in symmetrical ECs (two-electrode configuration, grey dots) and threeelectrode cell (red dots) normalized by $S_{N L D F T}\left(C_{\mathrm{e}, \text { int }}\right)$ as a function of atomic surface percentages of oxygen $\left(\mathrm{O}_{\mathrm{XPS}}\right)$ at $5 \mathrm{mV} \mathrm{s}^{-1}$; (d) cell capacitance vs. scan rate obtained in symmetrical ECs. Dotted curves are just guides for the eye.

Figure 5. EIS results for symmetrical ECs based on biochar-derived ACs in aqueous $1 \mathrm{M}$ $\mathrm{H}_{2} \mathrm{SO}_{4}$ : (a) Nyquist plots of activated carbons (inset: zoom on the first parts of the curves); (b) 
normalized capacitance $\left(C_{E I S} / C_{E I S, 1 m H z}\right)$ vs. frequency (inset: relaxation times vs. average micropore size).

Figure 6. GCD results for symmetrical ECs based on biochar-derived ACs in the voltage range from 0 to $0.9 \mathrm{~V}$ in $1 \mathrm{M}$ aqueous $\mathrm{H}_{2} \mathrm{SO}_{4}$ : (a) galvanostatic charge-discharge profiles at 2 $\mathrm{A} \mathrm{g}^{-1}$; (b) specific capacitance retention as a function of the applied current density; (c) Ragone plots of symmetrical ECs based on activated biochars synthesized in this work (full symbols) and extrapolated power-energy curves of the packaged device obtained from dividing the specific energy values by a factor of 3 (empty symbols). For comparison purposes, commercial electrochemical capacitor technologies have been included as the green zone, (adapted from $[85,86]$ ); (d) stability at $5 \mathrm{~A} \mathrm{~g}^{-1}$ of ECs based on TBC-K2.8 and TBCK3.6.

Figure 7. Leakage current and self-discharge results for symmetrical ECs based on biocharderived $\mathrm{ACs}$ in $1 \mathrm{M}$ aqueous $\mathrm{H}_{2} \mathrm{SO}_{4}$ : (a) time-dependent leakage current at $0.9 \mathrm{~V}$; (b) selfdischarge curves from $0.9 \mathrm{~V}$. 


\section{Table captions}

Table 1. Summary of biomass-derived carbon electrodes synthesized by pyrolysis and $\mathrm{KOH}$ activation for symmetrical ECs in aqueous acid media. 